\title{
Avaliação do Desempenho da Gestão Pública Municipal
}

\author{
http://dx.doi.org/10.21527/2237-6453.2020.53.138-165 \\ Recebido em: 18/12/2017 \\ Aceito em: $28 / 7 / 2020$

\begin{abstract}
José Ribamar Marques de Carvalho, ${ }^{1}$ Aila Katamara Queiroga Nóbrega, ${ }^{2}$ Clóvis Antônio Kronbauer ${ }^{3}$
\end{abstract}

\begin{abstract}
RESUMO
O presente estudo propôs-se a desenvolver uma metodologia baseada na análise multicriterial composta por indicadores de desempenho capaz de avaliar a performance dos municípios quanto aos aspectos sociais, econômicos e ambientais. Para tanto, a classificação metodológica segue o seguinte raciocínio: pesquisa aplicada, exploratória e descritiva, bibliográfica e documental de natureza quantitativa. O recorte geográfico e o teste piloto para aplicação da metodologia foi realizado nos 17 municípios localizados na microrregião de Sousa, PB. Os resultados demonstram que a aplicabilidade do modelo PROMETHEE II como método para definição de uma escala de avaliação - ou índice - das condições da gestão pública, a partir das dimensões econômica, social e ambiental de municípios, traz resultados relevantes a esse contexto. Entende-se que a ordenação obtida pelo método enfatiza que existe desigualdade entre os municípios localizados nessa região, necessitando estratégias e políticas públicas alinhadas a cada realidade e ao contexto da temática estudada.
\end{abstract}

Palavras-chave: Gestão pública. Indicadores de desempenho. Análise multicritério.

\section{PERFORMANCE ASSESSMENT OF PUBLIC MANAGEMENT MUNICIPAL}

\section{ABSTRACT}

This study aimed to develop a methodology based on multi-criteria analysis consists of performance indicators able to assess the performance of the municipalities regarding the social, economic and environmental aspects. Therefore, the methodological classification follows the following reasoning: applied research, exploratory and descriptive, bibliographical and documentary quantitative. The geographic divisions and the pilot test for application of the methodology was carried out in seventeen municipalities in the micro de Sousa, PB. The results demonstrate the applicability of PROMETHEE II model as a method for defining a rating scale - or index - the conditions of public administration, from the economic, social and environmental dimensions of municipalities brings significant results in this context. It is understood that the order obtained by the method emphasizes that there is inequality between the municipalities in the region in need of public strategies and policies aligned to each reality and context of the studied subject.

Keywords: Public management. Performance indicators. Multi-criteria analysis.

\footnotetext{
${ }^{1}$ Pós-doutor em Ciências Contábeis pelo PPGCONT-Unisinos. Doutor em Recursos Naturais pela Universidade Federal de Campina Grande (UFCG). Professor da Universidade Federal de Campina Grande (UFCG). http://lattes.cnpq.br/6335184086197610. https://orcid.org/00000003-3482-9231. profribamar@gmail.com

${ }^{2}$ Graduada em Ciências Contábeis pela Universidade Federal de Campina Grande (UFCG). http://lattes.cnpq.br/0150846329517881. https:// orcid.org/0000-0003-0250-6761. aila_katamara@hotmail.com

${ }^{3}$ Doutor em Contabilidad y Auditoría pela Universidad de Sevilla, Espanha. Professor da Universidade do Vale do Rio dos Sinos (Unisinos). http://lattes.cnpq.br/9586157708831103. https://orcid.org/0000-0002-1454-9243. clovisk@unisinos.br
} 
A demanda por ferramentas que contribuam para a institucionalização e o aperfeiçoamento das atividades de monitoramento é notadamente crescente (GONÇALVES et al., 2011). O interesse pela temática dos indicadores sociais, econômicos, ambientais e sua aplicação nas atividades ligadas ao planejamento governamental e ao ciclo de formulação e avaliação de políticas públicas, vêm crescendo no país nas diferentes esferas de governo e nos diversos fóruns de discussão dessas questões (JANNUZZI, 2005).

Feitosa (2012) demonstra que o mundo vivencia simultâneas crises financeiras, sociais e ambientais, que proporcionam o aumento do ceticismo em relação às possibilidades de crescimento sustentável. Essa preocupação amplia as oportunidades de debate em torno de algumas questões fundamentais: Seríamos mesmo capazes de conciliar crescimento com sustentabilidade econômica, ambiental e social? Ou, ainda, como planejar a expansão de nossas cidades de forma a garantir justiça social e qualidade de vida para a população?

Diante do exposto, entende-se que uma forma usual de monitorar e avaliar as ações dos gestores públicos seja por meio do uso de indicadores. De acordo com Ramos e Schabbach (2012), a avaliação e o monitoramento das ações que permeiam a gestão pública são fases imprescindíveis do planejamento estatal, ocupando também espaço crescente nas pesquisas acadêmicas. Sua atualidade no debate em torno da eficácia e do impacto das políticas públicas em diferentes áreas, é evidenciada pelos vários fóruns, encontros e redes de especialistas que tratam da temática, pela demanda oriunda de órgãos públicos e pela profissionalização dessa atividade em escala internacional.

Mediante a avaliação e o monitoramento, gestores, pesquisadores ou outros agentes podem examinar como suas ações estão sendo realizadas, ou como seus objetivos definidos estão sendo alcançados, retratando quais problemas interferem nas práticas e processos executados (FARIA, 2005).

Nesse sentido, acredita-se que instrumentos de apoio à decisão, como o uso de indicadores e índices aplicados ao contexto da gestão pública, embasado nas técnicas empiricamente testadas e consolidadas da análise multicritério, podem ajudar a entender melhor o complexo processo de decisão que envolve esses cenários, seja em termos de aspectos sociais, econômicos ou ambientais direcionados à gestão de cidades. Podem, ainda, proporcionar resultados significativos para o estabelecimento de estratégias públicas, possibilitando redirecionar objetivos e até mesmo a reformulação de políticas mais alinhadas a cada região de análise (DINIZ; MACEDO; CORRAR, 2012; BEZERRA; CARVALHO, 2018; ALMEIDA, 2013).

Embora não exista consenso teórico e metodológico acerca de quais modelos ou ferramentas devem ser utilizados no processo de planejamento e gerenciamento da gestão pública em municípios, algumas discussões emergem dos questionamentos em torno dessa problemática, seja na escolha de quais dimensões farão parte da metodologia e variáveis de análise, ou qual o peso delas, ou, ainda, quais atores sociais atribuirão pesos a essas variáveis. Para tanto, entende-se ser interessante que na propositura de um sistema de indicadores para a gestão pública, se adote técnicas de apoio à decisão como maneira de contribuir para a melhor estruturação do problema por meio de um método não hierárquico de análise multicritério, na tentativa de compreender as 
relações causais dos indicadores utilizados, melhorar a capacidade informativa desses índices, publicar os resultados alcançados e usar as medidas de desempenho como incentivos para a melhoria, conforme defendem Pekkanen e Niemi (2013).

Almeida (2013) reforça esse entendimento quando defende que existem diversas técnicas para subsidiar análises envolvendo várias dimensões e indicadores; dentre elas a análise multicritério. Essa técnica trata de problemas em contextos sem a possibilidade de externar resultados conclusivos por meio de um único critério ou variável, sendo necessário utilizar múltiplas variáveis que, se avaliadas em conjunto, tornam-se representativas de um resultado.

Sendo assim, a formulação de uma metodologia baseada em índices e indicadores focados na caracterização da dimensão social, econômica e ambiental por intermédio de critérios, funções de utilidade e de preferências, baseados na Teoria de Apoio à Decisão (Multicriteria decision analysis - MCDA), especialmente do Método PROMETHEE II (Preference Ranking Method for Enrichment Evaluation), apresenta-se como uma importante ferramenta capaz de contribuir para a melhoria da gestão desse panorama.

Acrescente-se, ainda, o fato de que dentro de um mesmo contexto geográfico, seja uma mesma região, localidade, Estado, etc., se pode perceber grandes diferenças nessas dimensões, o que comprova as diversidades existentes entre cada situação/conjuntura. É dentro deste aspecto que uma avaliação centrada em hierarquizar um problema decisório, com decisores de backgrounds diferenciados ${ }^{4}$ com base em informações sistematizadas em índices e indicadores, torna-se relevante para que se possa estimular o debate sobre o tema, com o intuito de propor melhorias nas regiões que apresentam acentuadas diferenças.

Nesse sentido, e dadas as colocações supra, fica estabelecido como premissa deste estudo o fato de que quanto maior for o esforço na identificação de diferentes formas de se calcular índices/indicadores, melhor será a construção de um sistema de indicadores para a gestão dos municípios, posto que algumas maneiras que foram adotadas e desenvolvidas, conforme pode-se constatar mais adiante (referencial teórico), apresentam limitações em lidar com medidas de natureza diversas em contextos e aspectos diferenciados.

Com base neste contexto, tem-se o problema que motivou esta pesquisa: Como desenvolver uma metodologia baseada na análise multicriterial composta por indicadores de gestão pública capaz de avaliar a performance dos municípios quanto aos aspectos sociais, econômicos e ambientais?

Expostos tais argumentos, e dada a importância da temática no contexto do monitoramento da gestão pública de municípios, o presente estudo justifica-se pelo fato de que pretende investigar essa temática envolvendo dimensões que adentram em questões de ordem econômica, social e ambiental, e se alinha à necessidade de avanços na pesquisa sobre Administração Pública focada nas políticas de gestão de recursos, uma vez que a gestão pública está passando de um modelo administrativo burocrático para um sistema gerencial (DINIZ; MACEDO; CORRAR, 2012).

\footnotetext{
${ }^{4}$ Considera-se aqui as várias etapas de brainstorm que subsidiaram a escolha das variáveis do modelo.
} 


\section{REFERENCIAL TEÓRICO}

\section{Avaliação de Desempenho na Gestão Pública}

A avaliação de desempenho no setor público surge como parte de um conjunto de esforços em prol do uso eficiente de recursos públicos (RIBEIRO, 2008). O surgimento do conceito específico de avaliação do desempenho estatal origina-se após a Segunda Guerra Mundial. Inicialmente, o seu desenvolvimento se deu por meio da busca dos economistas em desenvolver métodos para analisar as vantagens e custos de programas públicos. Com o passar do tempo, e com o aumento da complexidade do setor público, as avaliações precisaram ser reformadas e assumir um caráter mais abrangente, indo além da visão contábil econômica (CONTANDRIOPOULOS et al., 1997).

A medição de desempenho no setor público foi foco de Akim e Mergulhão (2015), quando apresentaram um panorama da produção intelectual no campo da medição de desempenho na gestão pública entre 1980 e fevereiro de 2013. Realizaram uma análise bibliométrica de citação e cocitação com o apoio dos softwares Sitkis, Netdraw e CiteSpace II. As bases de dados utilizadas foram a ISI Web of Science (WoS) - que reflete a pesquisa internacional -, e a SciELO - que reflete a pesquisa brasileira. $O$ estudo na WoS identificou os autores, periódicos, pares de documentos e instituições de pesquisas mais importantes. Além disso, o estudo na base da SciELO mostrou que a literatura sobre o campo estudado é dispersa. De forma geral, os resultados obtidos revelam que a medição de desempenho na gestão pública é um campo emergente.

Ramos e Schabbach (2012) consideram que a avaliação de desempenho constitui-se na determinação de valor de uma atividade, programa ou política, um julgamento tão sistemático e objetivo quanto possível, efetuado por avaliadores internos ou externos. Ao incorporar elementos valorativos e de julgamento, a avaliação contempla aspectos qualitativos, não se confundindo com o mero acompanhamento das ações governamentais.

Rua (2010) defende que a importância da utilização da avaliação no contexto da gestão pública é ressaltada pelos benefícios usufruídos pela própria administração governamental ao praticar o processo de avaliação. Alguns exemplos desses benefícios são: maiores níveis de aprendizagem institucional, maior legitimidade social e política ante a sociedade, maior promoção da transparência e do accounttability e fomento à democratização da gestão pública.

Mokate (2002) já pontuava algumas barreiras que são detectadas como entraves e ocasionadoras de resistência ao processo de desenvolvimento e aplicação de avaliações no ambiente público: a complexidade dos objetivos sociais e o grande número de variáveis e condições que afetam a atividade estatal criam uma "mística de complexidade" ao redor da avaliação. Essa mística acaba promovendo resistência ao desenvolvimento de práticas avaliativas, uma vez que as avaliações não têm sido percebidas como ferramentas de gestão. Isso se dá especialmente pelo fato de as avaliações serem realizadas basicamente por avaliadores externos e com o sentido de fiscalização, controle ou auditoria. A autora defende que o gestor precisa superar essas barreiras e transformar a imagem da avaliação de um "monstro" para um aliado no desenvolvimento da gestão pública. 
Dada a importância da avaliação de desempenho no contexto da gestão pública, é possível observar que diversos estudos, metodologias e ferramentas relacionadas ao uso de indicadores para subsidiar decisões e o monitoramento, foram desenvolvidos no contexto da gestão pública e envolveram aspectos sociais, econômicos ou ambientais. A seguir estão expostas algumas dessas experiências realizadas para avaliar a eficiência das políticas públicas nos mais variados segmentos.

Lima e Santos (2009) concentraram seu estudo na avaliação do desempenho da gestão pública em Entidades Federais indiretas do município de Manaus, com vistas a disponibilizar, para seus gestores e a sociedade em geral, informações que proporcionem um maior entendimento acerca da gestão dos recursos públicos. Os resultados encontrados possibilitaram avaliar os desempenhos orçamentário, financeiro e econômico, relativo ao exercício de 2006, além de permitir comparações entre as Entidades. Concluiu-se que a situação orçamentária nas quatro Unidades apresentou-se deficitária, enquanto a situação financeira indicou um pequeno déficit em uma Unidade e equilíbrio nas outras três. Os demais indicadores mostraram que houve aumento patrimonial em duas Entidades e nas outras duas houve redução.

Bogoni, Hein e Beuren (2011) utilizaram indicadores para investigar a relação existente entre o crescimento econômico, considerando o Produto Interno Bruto (PIB) e as variáveis que compõem os gastos públicos (em saúde e saneamento, gastos municipais em educação e cultura, conjunto de investimentos no município, gastos com habitação e com assistência e previdência) das maiores cidades da Região Sul do Brasil. O artigo apresenta um modelo matemático não linear multivariável que é avaliado empiricamente por meio de uma aplicação para os gastos públicos das maiores cidades da região Sul do Brasil. A partir da utilização do modelo, estimou-se o PIB para as cidades e comparou-se com os valores reais do PIB. Os resultados mostram um erro de estimação de $22,45 \%$ para uma confiabilidade de $85,16 \%$. Conclui-se que os gastos dos governos locais têm um importante papel no crescimento econômico.

Zucatto et al. (2009) propuseram indicadores de desempenho na gestão pública, com foco em escolas do Ensino Fundamental de um município do Noroeste do Rio Grande do Sul. Os indicadores do estudo possibilitam que fossem traçados comparativos entre as escolas, visando a apontar qual a escola que apresenta indicadores maiores ou menores auxiliando na investigação dos fatos que nela estejam ocorrendo. Além disso, uma vez familiarizada com essa prática, a gestão do município em análise poderia expandir a aplicação dessa ferramenta para outras áreas. Para realizar o estudo, observou-se o que a lei prevê: a Lei de Responsabilidade Fiscal manda avaliar os programas de governo em termos de eficiência, eficácia e efetividade, porém no presente estudo consideraram-se somente os dois primeiros. A eficiência faz referência aos recursos empregados nas escolas e a eficácia ao cumprimento de metas, ou seja, ao número de alunos aprovados. Partindo desse pressuposto, encontrou-se, junto a Escolas Municipais de Ensino Fundamental, a oportunidade de instituir um sistema de acompanhamento de indicadores de desempenho, criando-os e comparando-os entre as mesmas.

Borges (2012) desenvolveu uma proposta de indicadores de sustentabilidade de energia elétrica para a gestão pública junto ao setor residencial paraense, que poderá servir de modelo para a gestão pública do setor elétrico também em outros Estados brasileiros. A metodologia desta investigação baseou-se no suporte teórico do modelo 
PER, que envolve a relação pressão-Estado-resposta. Os resultados demonstraram que o aspecto econômico é o que melhor reflete o insumo elétrico nos domicílios paraenses. $\mathrm{O}$ aumento da renda média, reflexo da disponibilidade de eletricidade e do aumento do consumo desse insumo, teve papel importante na economia paraense. Já o aspecto socioambiental apresentou indicadores médios com tendência decrescente.

Zaman et al. (2012) investigaram o impacto dos indicadores financeiros sobre o desenvolvimento humano no Paquistão, usando dados anuais de 1975-2010. Os resultados revelam que indicadores financeiros estão intimamente associados com o crescimento econômico e o desenvolvimento humano no Paquistão, ou seja, existe uma forte correlação entre esses indicadores. Os indicadores financeiros estão intimamente associados ao crescimento econômico e ao desenvolvimento humano no Paquistão. A análise de decomposição por variância mostra que, entre todos os indicadores financeiros, a ampla oferta monetária exerceu a maior contribuição para as mudanças no capital humano.

Mendes et al. (2013) selecionaram indicadores de desempenho para avaliação do serviço de resíduos sólidos urbanos no município de Loulé, Portugal, por meio da adoção do Balanced Scorecard. As classificações gerais da avaliação do BSC foram de 51,7\%, 66,1\% e 70,1\% para 2009, 2010 e 2011, respectivamente, indicando uma melhoria no desempenho geral do serviço ao longo do tempo. Os resultados demonstram que o monitoramento das variações sazonais nas regiões turísticas é importante, pois essas variações podem ajudar a explicar mudanças anuais nos fatores que afetam o gerenciamento de serviços de resíduos, seus impactos na qualidade geral do serviço e o melhor momento para as medidas serem aplicadas. Os resultados indicaram que a ferramenta BSC pode auxiliar na gestão de resíduos urbanos em áreas turísticas com forte sazonalidade.

Carvalho e Curi (2015) propuseram uma metodologia composta por indicadores de gestão dos recursos hídricos capaz de medir a performance de municípios. A proposta deste estudo mostra-se como uma ferramenta que pode ser adotada por gestores públicos e demais partes interessadas a visualizar um núcleo de alternativas viáveis para a solução de problemas relacionados à gestão dos recursos hídricos em municípios, inerentes a fontes, demandas e gestão da água, gestão das cidades em relação à água, impactos sociais, econômicos e ambientais e preservação ambiental. A ideia básica esteve centrada em construir um modelo que apresente as características/propriedades dos indicadores e do índice, ser simples o suficiente para ser entendido e possa refletir mudanças nos contextos dos municípios. Há de se notar que esse modelo apresenta-se como um instrumento que pode ser adotado pela gestão dos recursos hídricos em cidades, considerando, principalmente, que nos dias atuais existem indícios de ineficiência da gestão pública, e maiores detalhes podem ser vistos no teste de viabilidade do modelo exposto no estudo de Carvalho (2013). As reflexões, as críticas e informações disponibilizadas neste trabalho propõem-se a ampliar a discussão em torno das políticas públicas na área da gestão dos recursos hídricos, de modo a consubstanciar resultados mais satisfatórios a esse contexto, seja por meio do entendimento e da ampliação das variáveis de decisão utilizadas no processo de construção de políticas relacionadas à gestão da água, seja para o aperfeiçoamento técnico dos órgãos gestores. 
Silva e Crisóstomo (2019) analisam os efeitos da gestão fiscal e da eficiência da gestão pública no desenvolvimento socioeconômico municipal. Utilizaram a análise envoltória de dados (data envelopment analysis - DEA) e regressão linear para analisar os 184 municípios cearenses, no período de 2007 a 2013. Os resultados indicam que a gestão fiscal e a eficiência da gestão pública influenciam positivamente o desenvolvimento socioeconômico municipal, sinalizando que os gestores públicos devem melhorar a eficiência de sua gestão e observar as regras de controle fiscal. Segundo os autores, a pesquisa contribui para a literatura da área de administração pública por aprofundar a discussão acerca das interações entre qualidade da gestão fiscal, eficiência da gestão pública e desenvolvimento socioeconômico, considerando os avanços dos modelos de gestão pública, de modo mais acentuado a emergência do modelo gerencial, que propõe uma gestão mais focada em resultados e com níveis de eficiência e eficácia mais elevados.

A partir dos modelos supracitados, observa-se a necessidade de entender melhor a maneira como tais índices ou indicadores foram propostos no intuito de definir melhores formas de calcular e analisar o contexto da gestão pública, posto ser uma das características implícitas existentes quando da elaboração de metodologias ou ferramentas que utilizam indicadores com medidas diferenciadas e que necessitam de mecanismos mais consistentes de mensuração e síntese.

Embora os estudos sejam considerados relevantes e desenvolvidos com temáticas diversas e em contextos geográficos específicos, é possível inferir que as metodologias desenvolvidas no contexto da gestão pública e que envolvem variáveis econômicas, sociais e ambientais, estão sempre necessitando de melhorias.

Dessa forma, argumenta-se que uma das ideias do estudo em apreço se constitui em minimizar algumas das deficiências encontradas nos estudos expostos, de modo que possa se buscar uma melhor adequação aos requerimentos dando importância relativa às características intrínsecas e extrínsecas da gestão pública em municípios, a partir de uma combinação de técnicas multicriteriais, especialmente do Método PROMETHEE II.

\section{Processo de Construção de Indicadores Baseados em Técnicas Multicriteriais}

Dentro do processo de decisão, em geral, são estabelecidos conflitos de interesse a partir das visões distintas dos decisores, quer sejam econômicas, sociais, políticas, ambientais, etc. Dessa forma, e por serem pessoas diferentes, é ao menos razoável aceitar que suas habilidades são desenvolvidas de maneiras diferentes e com comportamentos desiguais. Nesse sentido, a construção dos indicadores de sustentabilidade, em contexto da gestão das águas, a partir dos métodos da análise multicriterial, pode proporcionar o tratamento simultâneo de vários aspectos dentro do processo decisório.

A abordagem da análise multicriterial na construção de indicadores, pode ser embasada nas colocações de Weber (2002), Jollivet e Pavé (2002), quando demonstram a importância da modelagem multicriterial principalmente por dois motivos principais: pela natureza dos problemas a serem considerados (extremamente complexos, com várias dimensões envolvidas) e pela multiplicidade dos campos de especialização disciplinar envolvidos. 
Lucena (1999) já defendia, e hoje ainda é muito latente, que as decisões nos diversos setores da sociedade vêm sendo tomadas tradicionalmente com base em apenas um ou dois critérios, geralmente o econômico e/ou financeiro, por meio de técnicas monocriteriais, por exemplo, as de otimização da pesquisa operacional. Nestes tipos de métodos não é simples levar em consideração a presença e a importância de fatores subjetivos, sejam eles quantificáveis ou não, conduzindo, muitas vezes, à escolha de uma alternativa que não seria a mais adequada para atender às prioridades socioeconômicas essenciais de uma comunidade.

Para Silva, Cabrera e Teixeira (2006), a sociedade está vivendo o tempo dos parênteses, o tempo das eras. Esse tempo dos parênteses ocorre quando a sociedade se move de uma era industrial, centralizada, para uma era em que o uso da informação se torna a chave para o sucesso. A partir de tais necessidades e exigências crescentes, 0 pensamento multicriterial e multidecisor de tomadas de decisão começou a crescer e tomar forma.

Para Pompermayer (2003), muito se sabe a respeito de ações potenciais de conservação dos recursos naturais, principalmente daqueles em crescente escassez. Pouco se tem feito, no entanto, no sentido de evitar, num futuro próximo, sérios problemas diante das limitações desses recursos, particularmente os de natureza hídrica. Sendo assim, todo e qualquer esforço direcionado à recuperação, conservação e preservação dos recursos hídricos deve ser avaliado, para dar continuidade ao desenvolvimento econômico de forma sustentável, assegurando o bem-estar da humanidade.

Para a autora, várias são as ferramentas e métodos utilizados no campo do planejamento e gestão de recursos hídricos, como instrumentos de suporte às tomadas de decisão orientadas para a gestão contínua e integrada e o uso racional desses recursos. Vários são, também, os atores e agentes que, de uma forma ou de outra, estão envolvidos nessa questão e que atuam no processo de decisão, uma vez que a utilização de recursos hídricos envolve interesses múltiplos e, às vezes, conflitantes (POMPERMAYER, 2003).

Notadamente a problemática das tomadas de decisão nos dias atuais é caracterizada por um número crescente de alternativas e critérios conflitantes, dentre os quais os decisores necessitam selecionar, ordenar, classificar ou, ainda, descrever com detaIhes as alternativas a serem selecionadas, considerando múltiplos critérios. Em razão dessa complexidade, a metodologia do Multicritério de Apoio à Decisão objetiva fornecer, a quem necessita tomar uma decisão, as ferramentas necessárias e suficientes para habilitá-lo nas soluções de problemas em que vários pontos de vista, até mesmo contraditórios, devem ser levados em consideração (ARAÚJO; ALMEIDA, 2009).

Braga e Gobetti (2002) destacam que, raramente, uma decisão é tomada em razão de um único objetivo. Mesmo em problemas corriqueiros do dia a dia, como a compra de um equipamento doméstico de informática, em geral não utilizamos puramente o critério de mínimo custo. Outros fatores pesam na decisão: durabilidade do produto, garantia de manutenção, etc. Segundo esses autores, o processo decisório envolve múltiplos objetivos e múltiplos decisores, com visões diferenciadas acerca das metas a serem adotadas no planejamento e na gestão. 
A fim de lidar com os problemas que envolvem vários objetivos e alternativas de decisão simultaneamente ao processo decisório, de uma maneira lógica, os métodos multicriteriais de apoio à decisão procuram ir ao encontro de uma perspectiva holística, agregando toda a informação disponível, incluindo a de natureza subjetiva. O objetivo é alcançar uma maior transparência, sistematização e participação às decisões que serão tomadas (RANGEL; GOMES; MOREIRA 2009).

Os métodos multicritérios visam a apoiar o processo decisório (não necessariamente prover uma solução). Curi e Curi (2010) argumentam que os objetivos da análise multicriterial concentram-se basicamente em estruturar o problema e no processo de escolha entre duas ou mais alternativas de decisão. Na estruturação do problema, os maiores desafios estão na representação e organização formalizada do problema para aprendizagem, investigação/análise, discussão e busca da solução. Por sua vez, na escoIha entre duas ou mais alternativas surgem alguns problemas, por exemplo: leva-se em consideração diferentes critérios (consequências); podem ser contraditórios; podem existir vários decisores e diferentes opiniões; incorpora-se os juízos de valores dos decisores; a solução pode não satisfazer a todos decisores; usa-se dados qualitativos ou quantitativos (até com diferentes ordens de grandeza); pode-se ter mais de uma "solução ótima". A Figura 1 evidencia as fases da análise multicritério.

A Figura 1 pode ser bem mais explicada da seguinte forma: 1) dentro do processo decisório existe um problema que precisa ser analisado criticamente no intuito de identificar as vantagens e desvantagens no entorno da problemática; 2) necessidade de busca um estímulo para que exista a cooperação e não competição entre os decisores; 3 ) as propostas precisam ser bem analisadas para viabilizar as melhores soluções; 4) a ideia se apoia em dispor de uma metodologia clara e transparente. 5) finalmente, no último passo, aceitar a melhor decisão considerando as etapas anteriores, ou seja, buscando-se a melhor decisão ou o consenso entre as partes.

Figura 1 - Processo Decisório da Análise Multicriterial

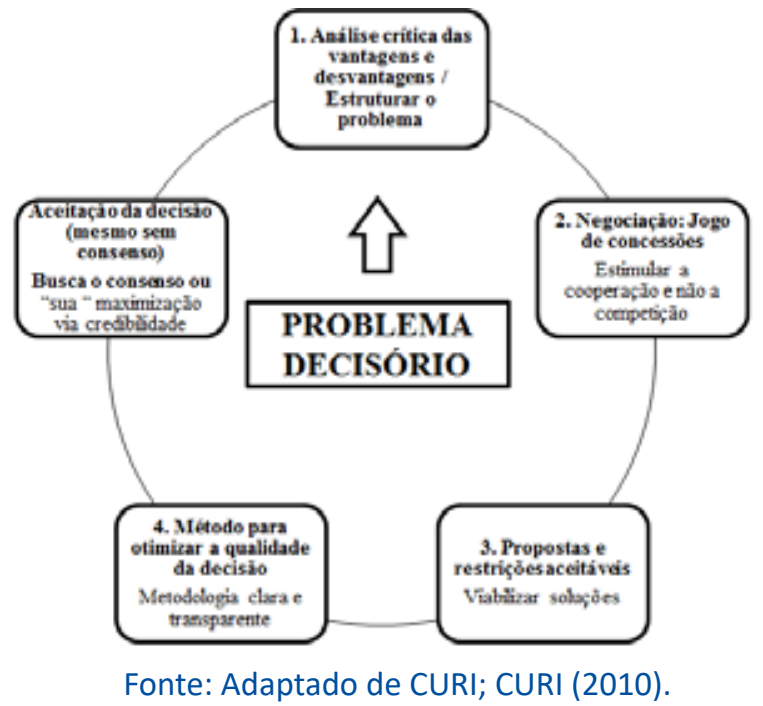

Nesse sentido, o que se pode perceber após tais entendimentos é que o processo de construção de indicadores como suporte à gestão pública de municípios pode levar em consideração o uso dessas técnicas multicriteriais, afinal envolvem múltiplos usuá- 
rios e múltiplas variáveis, o que o torna algo complexo e de difícil resolução. Isso porque a tentativa de resolver problema(s) a partir de objetivos conflitantes e com vários entendimentos, pode acarretar uma abrangência diversa.

$\mathrm{Na}$ área da gestão pública os decisores, ligados ao desenvolvimento econômico puro e simples, entendem que a melhor decisão refere-se à maximização do benefício econômico líquido, uma vez que os valores econômicos expressam o interesse da sociedade. Por outro lado, os grupos ambientalistas radicais pregam a preservação do meio ambiente em sua forma natural e se opõem a qualquer intervenção que venha transformá-lo. Observa-se, portanto, que existe entre estas duas posições extremadas um conjunto de possibilidades para se tentar soluções de compromisso (BRAGA; GOBETTI, 2002).

Rotineiramente, tanto em nossa vida profissional quanto privada, deparamo-nos com problemas cuja resolução implica o que consideramos uma tomada de decisão complexa. De modo geral, tais problemas possuem pelo menos algumas das seguintes características, conforme Gomes, Gomes e Almeida (2009):

- os critérios de resolução do problema são em número de, pelo menos, dois e conflitam entre si;

- tanto os critérios como as alternativas de solução não são claramente definidos e as consequências da escolha de dada alternativa com relação a pelo menos um critério não são claramente compreendidas;

- os critérios e as alternativas podem estar interligados, de tal forma que um critério parece refletir parcialmente outro critério, ao passo que a eficácia da escolha de uma alternativa depende de outra alternativa ter sido ou não também escolhida, no caso em que as alternativas não são mutuamente exclusivas;

- a solução do problema depende de um conjunto de pessoas, cada uma das quais tem seu próprio ponto de vista, muitas vezes conflitantes com os demais;

- $\quad$ as restrições do problema não são bem definidas, podendo mesmo haver alguma dúvida a respeito do que é critério e do que é restrição;

- alguns critérios são quantificáveis, ao passo que outros só o são por meio de julgamentos de valor efetuados sobre uma escala;

- a escala para dado critério pode ser cardinal, verbal ou ordinal, dependendo dos dados disponíveis e da própria natureza dos critérios.

Várias outras complicações podem surgir num problema real de tomada de decisão, mas esses sete aspectos supracitados caracterizam a complexidade de tal problema. Em geral, problemas dessa natureza são considerados mal-estruturados (GOMES; GOMES; ALMEIDA, 2009).

Lyra (2008) argumenta que o uso dos métodos multicritério para apoio à decisão se baseia no princípio de que, para as tomadas de decisão, a experiência e o conhecimento são, pelo menos, tão valiosos quanto os dados utilizados. Estes métodos analisam problemas incorporando critérios, tanto quantitativos quanto qualitativos.

É certo que o aumento da complexidade do processo de decisão na escolha de indicadores ambientais se dá por meio da quantidade de variáveis envolvidas, volume de informações, critérios estabelecidos, etc. Tudo isso dificulta a elaboração de presunções confiáveis e adequadas. Nesse sentido, “[...] sem o uso de ferramentas quantitativas e 
qualitativas adequadas ter-se-á, naturalmente, a perda de precisão e de relevância nas informações, pela limitação da capacidade humana de analisar todas as possíveis alternativas" (LYRA, 2008, p. 15).

Dentro desse contexto, entende-se que o uso dos métodos multicritério na área de recursos hídricos tem por finalidade auxiliar o processo de decisão, principalmente por ser um cenário em que vários critérios (indicadores) podem ser considerados (ambientais, sociais, econômicos, técnico operacionais, etc.), tornando o cenário complexo e de difícil decisão.

\section{MATERIAL E MÉTODOS}

Os procedimentos inerentes à execução da pesquisa são descritos a seguir, levando-se em consideração os seguintes aspectos: Classificação Metodológica da Proposta, Estrutura da Proposta, Recorte Geográfico e Temporal.

\section{Tipologia da Pesquisa}

No desenvolvimento do material e métodos que serão adotados, destacar-se-á inicialmente a importância da revisão bibliográfica na construção do quadro teórico do presente estudo com relação a conceitos inerentes à temática.

A pesquisa possui a seguinte classificação: quanto à finalidade, objetivos, procedimentos, natureza e quanto ao local de estudo.

Quanto à sua finalidade, classifica-se como uma pesquisa aplicada que objetiva gerar conhecimentos práticos e é dirigida à solução de problemas específicos. Envolve verdades e interesses locais, tendo como propósito resolver um problema específico, que, provavelmente, resultará em um produto diretamente aplicado, buscando atender às demandas sociais (SOUZA; FIALHO; OTANI, 2007).

Quanto aos objetivos, classifica-se como exploratória e descritiva. Exploratória, pois tem "como propósito de proporcionar maior familiaridade com o problema, com vistas a torná-lo mais explícito" (GIL, 2010, p. 27). Descritiva, porque serão descritas características dos municípios do Sertão da Paraíba, na qual se propõe investigar o "que é", ou seja, a descobrir as características de um fenômeno como tal. Nesse sentido, são considerados objeto de uma situação específica, um grupo ou indivíduo (RICHARDSON et al., 2007; GIL, 2010).

Quanto aos procedimentos, constitui-se como bibliográfica e documental. Gil (2010) apresenta muitos pontos de semelhança entre a pesquisa documental e a pesquisa bibliográfica, posto que nas duas modalidades utilizam-se dados já existentes. $A$ principal diferença está na natureza das fontes. A pesquisa bibliográfica fundamenta-se em material elaborado por autores com o propósito de ser lido por públicos específicos. Já a pesquisa documental vale-se de toda sorte de documentos, elaborados com finalidades diversas. [...] O que geralmente se recomenda é que seja considerada fonte documental quando o material consultado é interno à organização, e fonte bibliográfica quando for obtido em bibliotecas ou base de dados.

Quanto à natureza, classifica-se como quantitativa, uma vez que se pretende utilizar as técnicas para avaliação quantitativa e que o processo de construção de um trabalho científico, dependendo da natureza das informações, dos dados e das evidências 
levantadas, poderá empreender uma avaliação quantitativa, isto é: organizar, sumarizar, caracterizar e interpretar dados numéricos coletados (MARTINS; THEÓPHILO, 2009). Notadamente, procurar-se-á por fatos e causas do fenômeno a ser estudado por meio de medições de variáveis. A pesquisa (ou o método) quantitativa caracteriza-se pelo emprego da quantificação tanto nas modalidades de coleta de informações quanto no tratamento delas por meio de técnicas estatísticas, desde as mais simples às mais complexas (RICHARDSON et al., 2007).

\section{Recorte Geográfico e Temporal do Estudo}

O recorte geográfico do estudo focar-se-á em testar a viabilidade metodológica por intermédio de um estudo nos 17 municípios localizados na região da microrregião de Sousa, PB, que são: Aparecida, Cajazeirinhas, Condado, Lastro, Malta, Marizópolis, Nazarezinho, Paulista, Pombal, Santa Cruz, São Bentinho, São Domingos de Pombal, São Francisco, São José da Lagoa Tapada, Sousa, Vieirópolis e Vista Serrana. Observe a Figura 2.

Figura 2 - Mapa da Microrregião de Sousa, PB

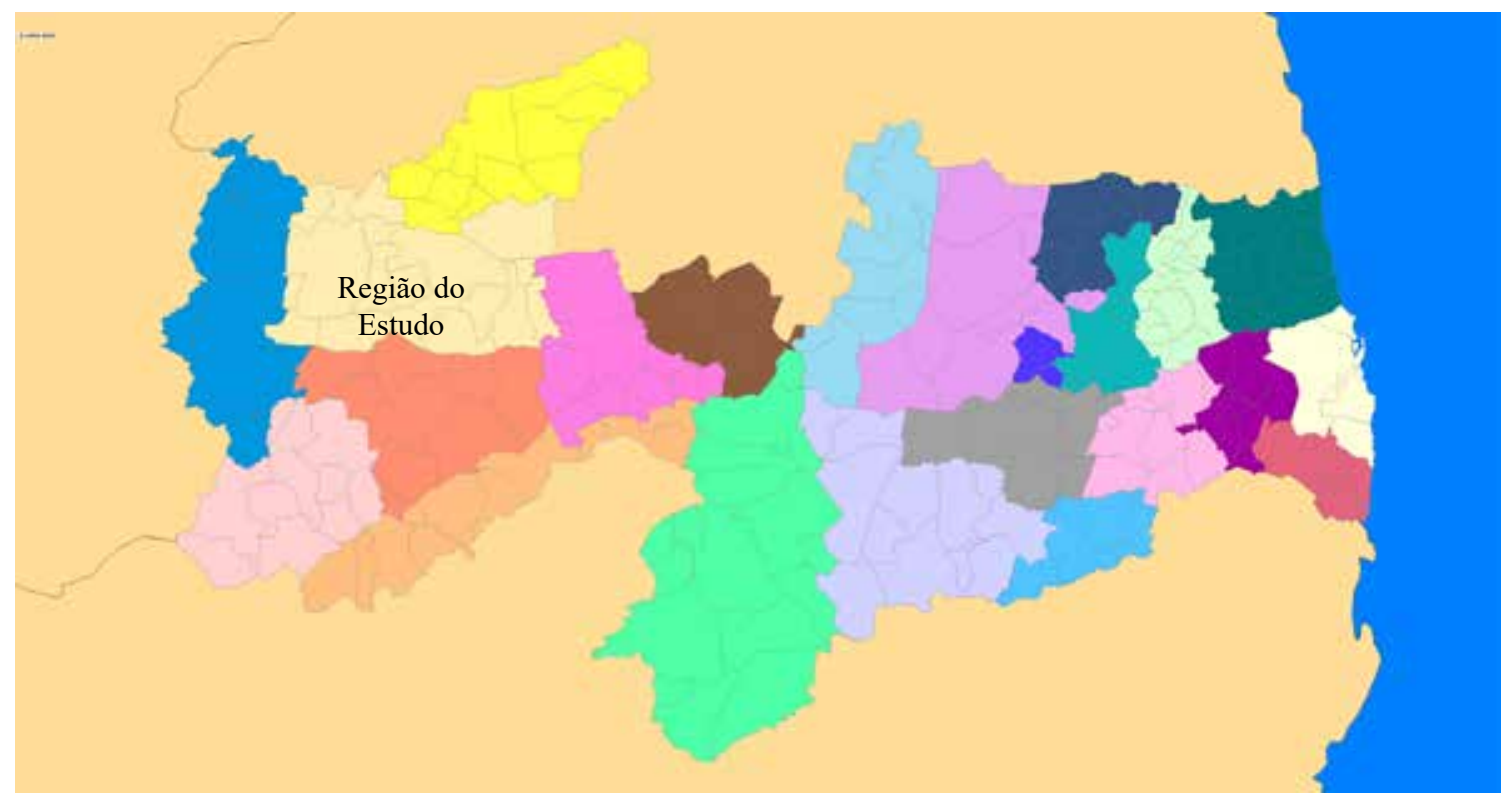

Fonte: http://geo.aesa.pb.gov.br/download.phtml, 2015.

Essa região foi escolhida por conveniência e pelo fato de estar localizada em uma microrregião que apresenta grande representatividade econômica para o Sertão do Estado da Paraíba, e supostamente necessita de melhores estratégias de gestão pública para minimizar os efeitos da disparidade econômica, social e ambiental.

Além disso, o desenvolvimento da microrregião de Sousa é influenciado também por sua característica climática natural. Nos últimos anos tem vivenciado períodos de baixíssimas precipitações pluviométricas, o que impacta diretamente nos níveis de produção e na geração de emprego e renda. Além disso, a instabilidade política local e nacional pode afetar a intermediação entre as esferas municipal, estadual e federal na obtenção de recursos e projetos de desenvolvimento para os municípios, a fim de minimizar os transtornos decorrentes dos impactos climáticos e da frágil economia lo- 
cal (BARBOSA, 2017). Configura-se, ainda, como uma microrregião que representa importância econômica e social para o Estado da Paraíba e, especialmente, para o Sertão Paraibano.

No que se refere ao recorte temporal, a metodologia foi desenvolvida e aplicada durante os meses de julho de 2014 a julho de 2015.

\section{Procedimentos Estatísticos}

O procedimento adotado para as comparações paritárias dos indicadores em relação aos municípios foi feito por meio do Método PROMETHEE II, que utiliza seis funções de preferências. A função de preferência utilizada na pesquisa foi do tipo Usual (tipo I) (Tabela 1).

Tabela 1 - Funções de preferência - Método Promethee

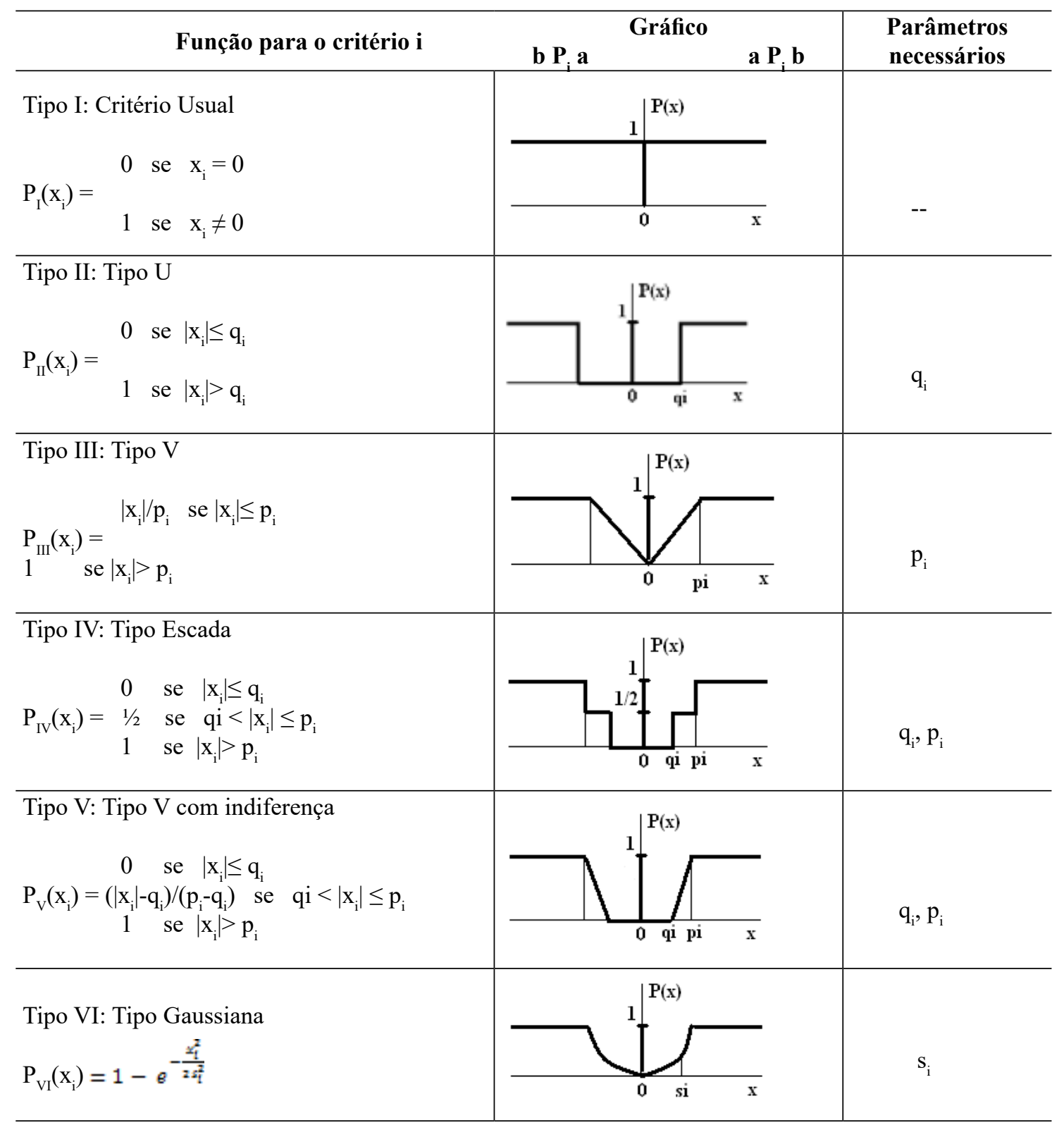


Após a comparação paritária entre os municípios e os critérios, foram analisados os fluxos positivos (phi+), negativos (phi) e líquidos (phi)) das avaliações para, assim, identificar os desempenhos das cidades investigadas.

Para dar suporte à construção metodológica foram utilizados os seguintes softwares: SPSS (Statistical Package for Social Science) versão 8.0 para o cálculo das estatísticas descritivas, e o Software Visual PROMETHEE, versão 1.3.

\section{APRESENTAÇÃO E DISCUSSÃO DOS RESULTADOS}

A seguir são apresentados os resultados do estudo realizado mediante a análise multicritério. São expostos os achados por meio do desempenho (ranking parcial), por dimensão e, posteriormente, o ranking global, que demonstra a situação da gestão pública dos municípios considerando as variáveis adotadas.

\section{Parâmetros de escolha dos Indicadores de Gestão Pública Municipal}

O modelo de análise, denominado Sistema de Indicadores para a Gestão Pública Municipal (SIGP), foi estruturado em 3 dimensões e 18 indicadores. Os parâmetros de seleção dos indicadores estão detalhados no Apêndice.

Procurou-se, nesta etapa, concentrar maior esforço em discutir exaustivamente os parâmetros de escolha de cada um dos indicadores, no intuito de construir um conjunto de informações interdependentes e interagentes combinadas em dimensões para que assim fosse possível analisar as formas de contribuição referentes à utilização de critérios de gestão pública municipal para avaliação da performance dos municípios quanto aos seus impactos econômicos, sociais e ambientais.

\section{Desempenho dos Municípios: Dimensão Econômica}

A dimensão econômica foi constituída por quatro indicadores (ver Tabela 2). Observa-se que os indicadores de Receita total per capita e FPM per capita apresentam médias elevadas de 2.565,19 e 1.300,68 respectivamente, e um desvio padrão também elevado de 821,32 e 608,42 , demonstrando que, apesar da média elevada, os valores estão muito dispersos em relação à média. Obtiveram também os valores mínimo e máximo maiores em relação aos outros indicadores. Os municípios com melhores desempenhos em relação ao indicador receita tributária per capita foram: Sousa, Pombal, São Domingos de Pombal, Aparecida e Lastro. Na situação menos confortável em relação aos demais foram Nazarezinho, Marizópolis e Cajazeirinhas.

Os municípios de Lastro, São Domingos de Pombal e São Francisco apresentaram maior dependência econômica em relação às transferências do Fundo de Participação dos Municípios (FPM), e com menor dependência per capita estão Sousa, Pombal e Paulista.

Os indicadores ICMS per capita e Receita Tributária Arrecadada per capita apresentaram médias baixas de 51,17 e 234,74 respectivamente, e um desvio padrão de 22,64 e 234,74, indicando que os valores apresentados não estão dispersos da média. Obtiveram também os valores mínimos e máximos menores em relação aos outros indicadores. 
No que se refere ao indicador ICMS per capita, observa-se que as melhores posições dizem respeito aos municípios de Lastro, São Domingos de Pombal e São Francisco. Já as piores são destacadas nos municípios de Pombal e Paulista.

Quanto ao indicador receita total per capita, Lastro, São Domingos e Vista Serrana estão nas melhores posições, seguidos de Sousa, Pombal e Paulista nas piores posições deste indicador. É importante frisar que a efetividade de alocar recursos públicos nessa dimensão, conforme prioridades do gestor público, equivale necessariamente a mais utilidades públicas, uma vez que são essenciais para viabilizar as demandas da sociedade em termos de arrecadação tributária para atender às necessidades da população.

Para Marcello (2014), a causa dos efeitos financeiros de determinado local está ligada ao seu desenvolvimento, tendo uma certa relação com a gestão pública, pois é de fundamental importância para o bem-estar da sociedade a geração de emprego e renda no município. Assim, o gestor público pode promover ações que sejam favoráveis à geração de emprego para a população, incentivando novas organizações que produzam um ambiente favorável para atender aos anseios da gestão e da sociedade.

Tabela 2 - Estatística descritiva dos indicadores econômicos

\begin{tabular}{|c|c|c|c|c|}
\hline \multirow[b]{2}{*}{ Municípios } & \multicolumn{4}{|c|}{ DIMENSÃO ECONÔMICA } \\
\hline & $\begin{array}{c}\text { Receita tributária } \\
\text { per capita }\end{array}$ & $\begin{array}{l}\text { FPM per } \\
\text { capita }\end{array}$ & $\begin{array}{l}\text { ICMS per } \\
\text { capita }\end{array}$ & $\begin{array}{l}\text { Receita total } \\
\text { per capita }\end{array}$ \\
\hline Aparecida & 71,15 & 840,77 & 177,98 & 1914,38 \\
\hline Cajazeirinhas & 37,12 & 1893,64 & 318,54 & 3105,72 \\
\hline Condado & 27,30 & 1022,39 & 191,23 & 2121,70 \\
\hline Lastro & 62,97 & 2465,91 & 393,24 & 4313,31 \\
\hline Malta & 39,09 & 1211,01 & 225,75 & 2407,65 \\
\hline Marizópolis & 26,32 & 1061,72 & 179,75 & 2292,65 \\
\hline Nazarezinho & 24,68 & 937,58 & 178,79 & 2100,96 \\
\hline Paulista & 47,00 & 753,81 & 137,85 & 1845,24 \\
\hline Pombal & 94,51 & 560,72 & 130,38 & 1814,57 \\
\hline Santa Cruz & 51,29 & 1045,09 & 198,11 & 2023,49 \\
\hline São Bentinho & 33,68 & 1563,86 & 284,45 & 2470,70 \\
\hline São Domingos de Pombal & 70,94 & 2267,40 & 356,63 & 4086,44 \\
\hline São Francisco & 51,06 & 2032,08 & 336,21 & 3654,73 \\
\hline São José da Lagoa Tapada & 35,36 & 895,44 & 174,67 & 2252,96 \\
\hline Sousa & 97,92 & 401,70 & 178,61 & 1476,04 \\
\hline Vieirópolis & 35,71 & 1306,06 & 216,16 & 2578,66 \\
\hline Vista Serrana & 63,86 & 1852,42 & 312,21 & 3148,95 \\
\hline Média & 51,17 & 1300,68 & 234,74 & 2565,19 \\
\hline Desvio padrão & 22,64 & 608,42 & 81,33 & 821,32 \\
\hline Mínimo & 24,68 & 401,70 & 130,38 & 1476,04 \\
\hline Máximo & 97,92 & 2465,91 & 393,24 & 4313,31 \\
\hline
\end{tabular}

Fonte: Dados da pesquisa, 2015. 
Uma avaliação parcial, combinando todos os indicadores da dimensão econômica (Tabela 2), demonstra que Lastro $(0,84)$, São Domingos de Pombal $(0,81)$, São Francisco $(0,59)$, Vista Serrana $(0,53)$ e Cajazeirinhas $(0,37)$ se destacam, seguidos de Malta, São Bentinho e Vieirópolis, todos com fluxos líquidos positivos (Phi). Os municípios com fluxos líquidos negativos (Phi) maiores e, consequentemente, com as posições menos confortáveis, foram: Paulista $(-059)$, Nazarezinho $(-0,53)$, São José da Lagoa Tapada $(-0,468)$, Pombal $(-0,468)$, Sousa $(-0,37)$, Condado $(-0,34)$, Marizópolis $(-0,28)$, Aparecida $(-0,28)$ e Santa Cruz (-009).

\section{Desempenho dos Municípios: Dimensão Social}

Na dimensão social observa-se que os indicadores Gastos em Educação per capita, Gastos de Saúde per capita, Gastos em Urbanismo per capita, Gastos em Assistência Social per capita apresentam médias elevadas de 717,73, 477,80, 203,66, 111,79 respectivamente, e um desvio padrão também elevado de 236,36, 213,68, 89,15, 59,53, demonstrando que, apesar da média elevada, os valores estão muito dispersos em relação à média. Os mesmos indicadores também apresentam os valores mínimos maiores.

Em relação aos valores máximos maiores, destacaram-se os indicadores Gastos em Educação per capita, Gastos de Saúde per capita, Gastos em Urbanismo per capita, Gastos em Assistência Social per capita e Gastos em Cultura per capita.

Os indicadores IDH-M, Gastos em Segurança per capita, Gastos em Habitação per capita, Gastos em Transporte per capita, Gastos em Cultura per capita, apresentam médias baixas de $0,59,2,32,2,53,11,47,16,08$ respectivamente, e um desvio padrão de $0,04,8,05,9,55,19,89,19,67$, indicando que os valores expostos não estão dispersos da média. Obtiveram os valores mínimos menores, incluindo o indicador Gastos de Saúde per capita. Apresentaram, também, os valores máximos menores, exceto o indicador Gastos em Cultura per capita.

Como nota-se nos Gastos com Saúde, Cajazeirinhas e São Bentinho não apresentam investimentos neste tipo de função. Lastro e São Francisco destacam-se.

Já os Gastos com Educação sobressaem nas cidades de São Domingos de Pombal, Lastro, Cajazeirinhas e Vieirópolis, enquanto os municípios com menores investimentos na educação foram Sousa, Pombal e Condado.

Os Gastos com Transporte em maior destaque em termos de investimentos são para os municípios de Marizópolis, Lastro, São Francisco e Pombal. Já o pior desempenho neste indicador foi evidenciado pelos dos municípios de Paulista, Cajazeirinhas e Vista Serrana, que não tiveram preocupação em investir ou evidenciar esse tipo de função. Esse cenário reforça o que Fernandes et al. (1998) já enfatizavam afirmando que o gasto social é aquele gasto voltado para a melhoria, a curto e longo prazos, das condições de vida da população.

Os municípios de toda a região investigada praticamente não investem em segurança, o que demonstra certa falta de zelo, conforme defende Bittencourt (2013), posto que se entende dever do Estado proporcionar os meios necessários à segurança pública, atrelado a isso a contrapartida relacionada à responsabilidade da sociedade. Bittencourt (2013) ainda argumenta que a competência da Guarda Municipal, mesmo sendo facultativa por parte da Administração Pública municipal, é importante na defesa da 
ordem pública, dos interesses públicos e dos direitos fundamentais. Por ser um instrumento da atividade do Estado, a sua finalidade está alinhada a auxiliar as instituições democráticas e o exercício institucionalizado da democracia por meio da Constituição, garantindo harmonia social e coibindo arbitrariedades que lesem bens jurídicos importantes.

Os gastos municipais na função de urbanismo são melhores em Vista Serrana, São Francisco e Lastro, uma vez que se destaca em relação aos demais municípios no que se refere à função. Malta, São José da Lagoa Tapada e Sousa precisam concentrar melhores investimentos e estratégias de gestão pública para potencializar a realidade local municipal.

Os investimentos com Assistência Social são mais evidentes nas cidades de Lastro, São Francisco e Cajazeirinhas. O município de Sousa e Marizópolis apresentam as piores posições.

Os gastos com habitação ainda são incipientes em quase todos os municípios, exceto São José da Lagoa Tapada e Marizópolis. Já os gastos com cultura destacam-se em São Francisco, Vieirópolis e Condado. Lastro, São José da Lagoa Tapada, Marizópolis e Vista Serrana não têm focado estratégias neste tipo de função.

No que se refere à dimensão social, é possível verificar, na Tabela 3, que São Francisco, Lastro, São Domingos de Pombal e Santa Cruz se destacam, seguidos de Vieirópolis, Malta e Marizópolis, considerados com fluxos líquidos $\left(\mathrm{Phi}^{+}\right)$positivos. Os municípios com fluxos líquidos (Phi') negativos foram: São José da Lagoa Tapada, Nazarezinho, Sousa, Cajazeirinhas, Aparecida, Condado, Paulista, Pombal, São Bentinho, Vista Serrana.

\section{Desempenho dos Municípios: Dimensão Ambiental}

$\mathrm{Na}$ dimensão ambiental (Tabela 4), observa-se que os indicadores apresentam coeficientes de Índice de Atendimento Total de Água, Domicílios particulares permanentes, Gastos em Saneamento per capita 59,41, 27,43, 14,32 respectivamente, e um desvio padrão também elevado de 22,89, 20,40, 17,32, demonstrando que os valores estão muito dispersos em relação à média. Observa-se que as rubricas, no geral, ainda são muito baixas para atender às demandas da sociedade; veja, por exemplo, o indicador gasto com saneamento básico per capita que, em nove cidades, o gestor público não alocou recursos, como é o caso de Cajazeirinhas, Condado, Marizópolis, Paulista, Pombal, Santa Cruz e São Bentinho. Os demais municípios os valores são relativamente baixos.

Os indicadores Existência de Aterro Sanitário no município ou se existe projeto de instalação e Gastos em Gestão Ambiental per capita, apresentaram médias baixas de 0,26, 2,36 respectivamente, e um desvio padrão de 0,30, 4,14. Os indicadores Gastos em Saneamento per capita, Gastos em Gestão Ambiental per capita, Existência de Aterro Sanitário no município ou se no município existe projeto de execução, apresentaram valores mínimos menores, e os indicadores Existência de Aterro Sanitário no município ou se no município existe projeto de estabelecimento de Gastos em Gestão Ambiental per capita, demonstraram valores máximos menores. 


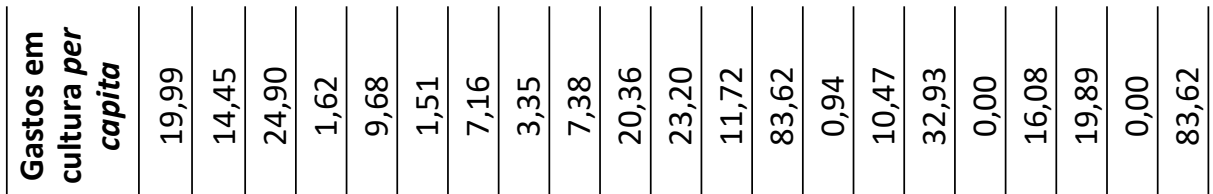

ह ॠ

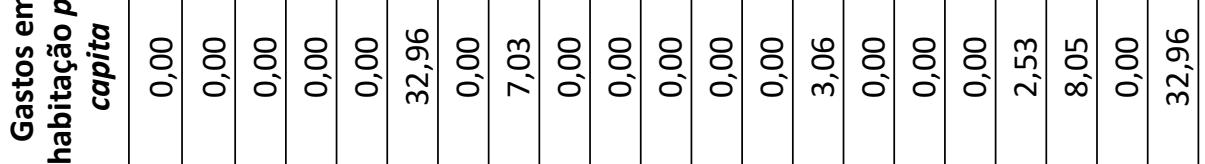

$\frac{10}{\frac{2}{2}}$

至

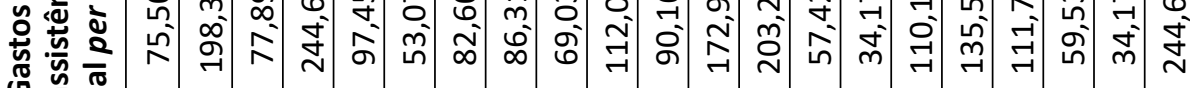
ऽ

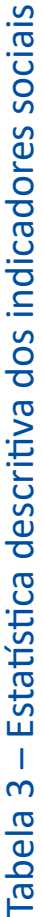

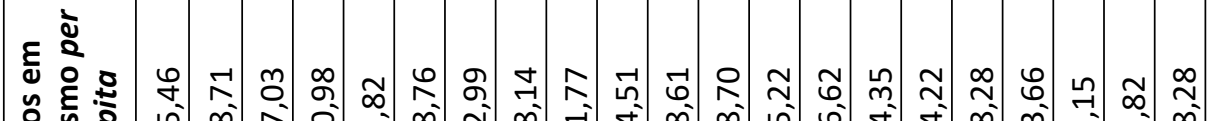

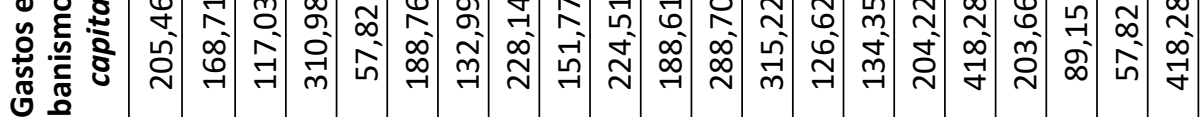

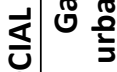

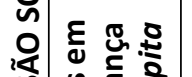

乡

这

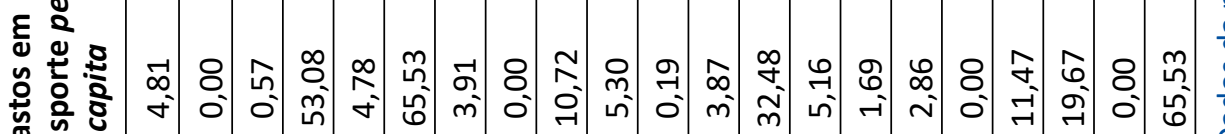
ธั

¿̀

๘

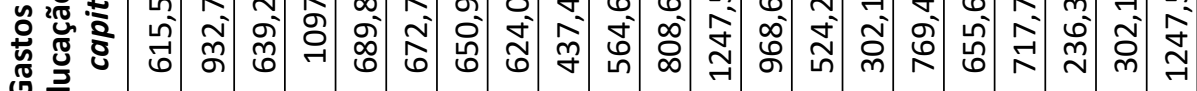
궁

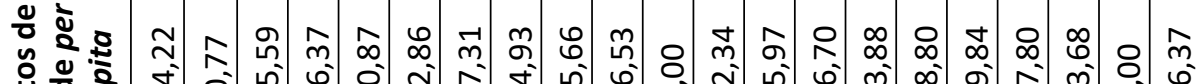

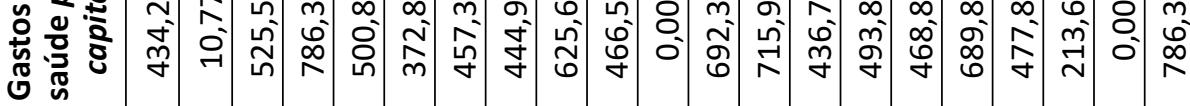

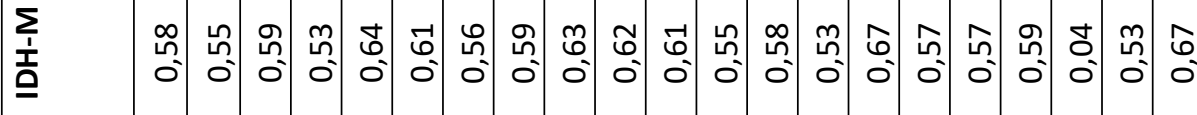

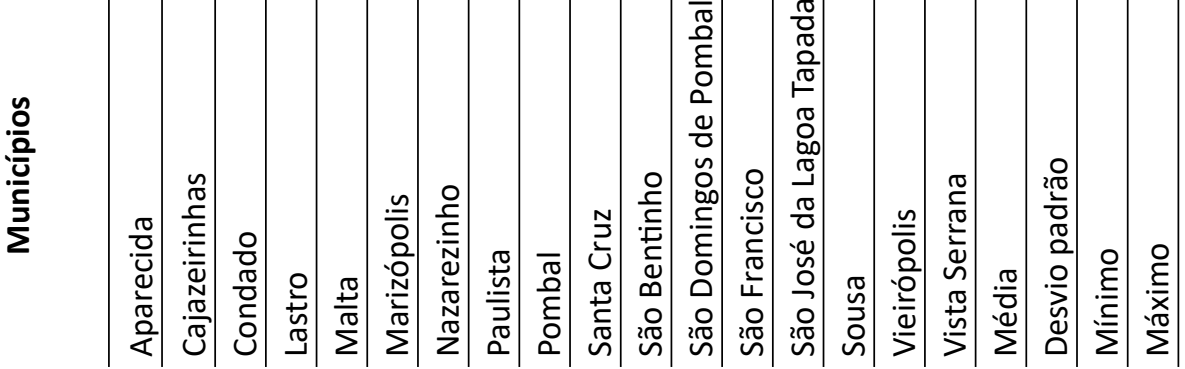


Silva e Silva (2015) afirmam que, se poucos recursos são direcionados a essas funções, como retrata os resultados deste estudo, como função de saneamento, gastos com gestão ambiental e não existência de projeto de aterro sanitário, entende-se que a gestão municipal não está preocupada com o bem público e sim com o interesse dos governantes. Como os investimentos nessas rubricas não proporcionam publicidade imediata à ação do gestor, eles não são considerados prioritários para influenciar as decisões de votos, afetando demasiadamente aspectos inerentes à gestão ambiental local que se apresenta como um problema da gestão pública e que necessita de maior investimento.

Tabela 4 - Estatística descritiva dos indicadores ambientais

\begin{tabular}{|c|c|c|c|c|c|}
\hline \multirow[b]{2}{*}{ Municípios } & \multicolumn{5}{|c|}{ DIMENSÃO AMBIENTAL } \\
\hline & $\begin{array}{c}\text { Gastos em } \\
\text { saneamento } \\
\text { per capita }\end{array}$ & $\begin{array}{c}\text { Gastos } \\
\text { em gestão } \\
\text { ambiental } \\
\text { per capita }\end{array}$ & $\begin{array}{c}\text { Domicílios } \\
\text { particulares } \\
\text { permanentes }\end{array}$ & $\begin{array}{l}\text { Existência ou } \\
\text { projeto de } \\
\text { instalação de } \\
\text { aterro sanitário } \\
\text { no município } \\
\end{array}$ & $\begin{array}{l}\text { Índice de } \\
\text { Atendimento } \\
\text { Total de Água }\end{array}$ \\
\hline Aparecida & 15,48 & 0,00 & 4,20 & 0,50 & 56,14 \\
\hline Cajazeirinhas & 0,00 & 0,00 & 11,40 & 0,00 & 42,41 \\
\hline Condado & 0,00 & 0,00 & 37,00 & 0,00 & 83,56 \\
\hline Lastro & 22,12 & 0,00 & 12,00 & 0,50 & 49,45 \\
\hline Malta & 8,14 & 0,00 & 73,30 & 0,00 & 88,71 \\
\hline Marizópolis & 0,00 & 10,96 & 14,70 & 0,00 & 90,13 \\
\hline Nazarezinho & 28,40 & 0,00 & 18,30 & 0,50 & 43,73 \\
\hline Paulista & 0,00 & 5,83 & 29,20 & 0,00 & 30,93 \\
\hline Pombal & 0,00 & 14,26 & 60,00 & 0,50 & 91,41 \\
\hline Santa Cruz & 0,00 & 0,00 & 27,50 & 0,00 & 61,30 \\
\hline São Bentinho & 0,00 & 4,34 & 37,40 & 0,00 & 70,63 \\
\hline São Domingos de Pombal & 26,41 & 1,65 & 25,60 & 0,00 & Sem dados \\
\hline São Francisco & 41,40 & 2,69 & 13,20 & 0,50 & Sem Dados \\
\hline São José da Lagoa Tapada & 0,03 & 0,00 & 16,30 & 0,50 & 44,38 \\
\hline Sousa & 34,63 & 0,38 & 64,60 & 1,00 & Sem Dados \\
\hline Vieirópolis & 57,27 & 0,00 & 1,60 & 0,50 & 19,51 \\
\hline Vista Serrana & 9,48 & 0,00 & 20,00 & 0,00 & Sem Dados \\
\hline Média & 14,32 & 2,36 & 27,43 & 0,26 & 59,41 \\
\hline Desvio padrão & 17,32 & 4,14 & 20,40 & 0,30 & 22,89 \\
\hline Mínimo & 0,00 & 0,00 & 1,60 & 0,00 & 19,51 \\
\hline Máximo & 57,27 & 14,26 & 73,30 & 1,00 & 91,41 \\
\hline
\end{tabular}

Fonte: Dados da pesquisa, 2015.

Na Dimensão Ambiental é possível observar, no Tabela 4 , que Sousa, Pombal e São Francisco se destacam seguidos de Malta, São Domingos de Pombal, São Bentinho e Nazarezinho, todos com o Phi positivos. Marizópolis apresentou fluxo líquido zero, uma vez que seus fluxos positivos foram iguais aos negativos. Os municípios com fluxos líquidos (Phi) negativos foram: Cajazeirinhas, Santa Cruz, Vista Serrana, Vieirópolis, Condado, Paulista, São José da Lagoa Tapada, Aparecida e Lastro. 


\section{Ranking Final do Desempenho da Gestão Pública Municipal obtido pelo SIGP}

Diante dos resultados obtidos pelas análises de todos os indicadores, foi gerado o ranking final do desempenho dos municípios, conforme evidencia a Tabela 5.

Como pode-se observar, o ranking final obtido sinaliza que o município de São Francisco obteve o melhor desempenho, que o coloca em 1a posição no ranking. Esse resultado explica-se pelo fato de o município ter obtido bons resultados nas três dimensões analisadas (econômica, social e ambiental). Os indicadores que contribuíram para esse bom desempenho foram: Receita Total per capita, Gastos em Educação per capita e Gastos em Saneamento per capita.

Tabela 5 - Ranking Final do SIGP

\begin{tabular}{c|l|c|c|c}
\hline Ranking & \multicolumn{1}{|c|}{ Municípios } & Phi & Phi+ & Phi- \\
\hline 1 & São Francisco & 0,476 & 0,649 & 0,174 \\
\hline 2 & São Domingos de Pombal & 0,323 & 0,569 & 0,247 \\
\hline 3 & Lastro & 0,319 & 0,576 & 0,257 \\
\hline 4 & Malta & 0,066 & 0,448 & 0,382 \\
\hline 5 & Vista Serrana & 0,056 & 0,417 & 0,361 \\
\hline 6 & Vieirópolis & 0,028 & 0,431 & 0,403 \\
\hline 7 & São Bentinho & 0,017 & 0,427 & 0,410 \\
\hline 8 & Pombal & 0,000 & 0,424 & 0,424 \\
\hline 9 & Santa Cruz & $-0,010$ & 0,399 & 0,410 \\
\hline 10 & Sousa & $-0,035$ & 0,406 & 0,441 \\
\hline 11 & Marizópolis & $-0,056$ & 0,413 & 0,469 \\
\hline 12 & Cajazeirinhas & $-0,146$ & 0,326 & 0,472 \\
\hline 13 & Aparecida & $-0,153$ & 0,340 & 0,493 \\
\hline 14 & Condado & $-0,167$ & 0,319 & 0,486 \\
\hline 15 & Paulista & $-0,208$ & 0,333 & 0,542 \\
\hline 16 & Nazarezinho & $-0,240$ & 0,299 & 0,538 \\
\hline 17 & São José da Lagoa Tapada & $-0,271$ & 0,330 & 0,601 \\
\hline
\end{tabular}

Fonte: Dados da pesquisa, 2015

O município de São Domingos de Pombal apresentou segunda posição no ranking. Esse desempenho deu-se pelo destaque dos mesmos indicadores do município de São Francisco, porém os resultados apresentados foram menores; assim, São Domingos de Pombal foi superado por São Francisco.

Lastro apresenta-se na terceira melhor posição. O resultado desse município foi considerado satisfatório, uma vez que só foi superado pelas cidades de São Francisco e São Domingos de Pombal, sendo os indicadores de receita total per capita, gastos em educação per capita e índice de atendimento total de água os mais representativos.

O município de Malta, assim como Lastro, apresentou os indicadores receita total per capita, gastos em educação per capita e índice de atendimento total de água como mais relevantes, porém obteve valores menores, conseguindo alcançar quarta posição abaixo do município do Lastro. 
Vista Serrana foi classificado na quinta posição, pelo destaque de desempenho dos indicadores de receita total per capita, gastos de saúde per capita e domicílios particulares permanentes.

Na sexta posição ficou Vieirópolis, contribuindo para tal posição os indicadores de receita total per capita, gastos em educação per capita e gastos em saneamento per capita.

O município de São Bentinho ficou na sétima posição, refletido pelos indicadores de receita total per capita, gastos em educação per capita e índice de atendimento total de água.

Pombal apresenta-se na oitava posição, decorrente dos indicadores receita total per capita, gastos de saúde per capita e índice de atendimento total de água.

O município de Santa Cruz ficou na nona posição, sendo os indicadores de receita total per capita, gastos em educação per capita e índice de atendimento total de água os mais representativos.

Na décima posição do ranking está o município de Sousa, quando os indicadores que tiveram relevância para obter tal posição foram: receita total per capita, gastos de saúde per capita e domicílios particulares permanentes.

Marizópolis, por sua vez, ficou na décima primeira posição, com destaque nos indicadores de receita total per capita, gastos em educação per capita e índice de atendimento total de água.

Cajazeirinhas alcançou a décima segunda posição com os indicadores receita total per capita, gastos em educação per capita e índice de atendimento total de água.

$\mathrm{Na}$ décima terceira posição ficou o município de Aparecida, com os indicadores receita total per capita, gastos em educação per capita e índice de atendimento total de água.

Condado apresenta-se com a décima quarta posição em virtude dos indicadores receita total per capita, gastos em educação per capita e índice de atendimento total de água em destaque.

O município de Paulista ficou na décima quinta posição no ranking, quando os indicadores que o levaram a tal posição foram: receita total per capita, gastos em educação per capita e índice de atendimento total de água.

Nazarezinho obteve a penúltima posição no ranking (décima sexta). Sendo assim, esse município foi superado por todos os demais com exceção de São José da Lagoa Tapada, que ficou na pior posição.

Na última posição do ranking ficou o município de São José da Lagoa Tapada, que não superou nenhuma cidade (décima sétima posição). Esse município necessita de maiores estratégias públicas, uma vez que os indicadores de gastos em habitação per capita, gastos em transporte per capita, gastos em saneamento per capita e gastos em gestão ambiental per capita, demonstraram inferioridade, necessitando, assim, de meIhores esforços da gestão pública. 
A seguir são apresentadas as considerações finais do trabalho, que objetivou desenvolver e aplicar uma metodologia baseada na análise multicriterial composta por indicadores de gestão pública, estruturados de forma sistêmica para auferir a performance da gestão pública municípios da região investigada.

\section{CONSIDERAÇÕES FINAIS}

Mediante a aplicação do método PROMETHEEE II no estudo de caso, percebe-se que este método apresenta sensibilidade à variação dos parâmetros utilizados em razão dos tipos de critérios gerais adotados por ele e pelas funções de utilidade. As variações obtidas em cada dimensão apresentam resultados com níveis bem próximos, o que demonstra que, muito embora a situação em alguns municípios seja superior aos demais, necessitam de esforços tanto dos órgãos e gestores governamentais quanto das partes interessadas em busca da melhoria e da qualidade de vida da população, conforme defendem Carvalho e Curi (2014).

Os resultados obtidos pelo SIGP demonstram que a aplicabilidade do modelo PROMETHEE II como método para definição de uma escala de avaliação - ou índice das condições da gestão pública, a partir das dimensões econômica, social e ambiental nos municípios, traz resultados relevantes a esse contexto. A ordenação obtida por meio do método enfatiza que existe desigualdade entre os municípios localizados nessa região, necessitando de estratégias e políticas públicas alinhadas a cada realidade e ao contexto da temática estudada.

Como observa-se, a situação mais confortável apresenta-se nos municípios São Francisco, São Domingos de Pombal, Lastro, Malta, Vista Serrana, Vieirópolis, São Bentinho e Pombal. No contraponto, os municípios em situação menos confortável em relação à gestão pública são: Condado, São José da Lagoa Tapada, Nazarezinho, Paulista, Aparecida, Cajazeirinhas, Marizópolis, Sousa e Santa Cruz.

As reflexões, as críticas e as informações disponibilizadas neste trabalho, propõem-se a ampliar a discussão em torno das políticas públicas na área da gestão pública de modo a consubstanciar resultados mais satisfatórios a esse contexto, seja por meio do entendimento e ampliação da participação popular no processo de construção dessas políticas sociais, econômicas e ambientais, seja para o aperfeiçoamento técnico dos órgãos gestores.

Torna-se relevante ressaltar que o modelo foi desenvolvido com a finalidade principal de propor e validar o emprego da metodologia, limitando-se à priorização dos municípios estudados (CARVALHO; CURI 2015). De maneira geral, é interessante salientar que, possivelmente, outros indicadores poderiam ter sido considerados na análise, como também outras alternativas de soluções incorporadas, o que, obviamente, modificaria o resultado final da análise.

Como limitação do estudo, aponta-se o fato de que outras variáveis poderiam ter sido incluídas/excluídas, uma vez que a subjetividade na escolha dos parâmetros de análise são sempre subjetivas e cabem interpretações diferenciadas. Também, adotar outras funções de utilidade do método, uma vez que se fez o uso apenas de uma das funções (Tipo I Usual). Outra limitação concentra-se no fato de que se adotou uma amostra por conveniência. 
Sugere-se aplicar o modelo em outras regiões do Estado da Paraíba ou em todos os municípios, bem como em outros Estados brasileiros, no intuito de enfatizar sua aplicação para o delineamento de políticas públicas eficientes.

\section{AGRADECIMENTOS}

Ao Conselho Nacional de Desenvolvimento Científico e Tecnológico (CNPq) pelo apoio concedido durante a realização do estudo na fase de execução do Projeto.

\section{REFERÊNCIAS}

AKIM, É. K.; MERGULHÃO, R. C. Panorama da produção intelectual sobre a medição de desempenho na gestão pública. Revista de Administração Pública, 49(2), p. 337-366, mar./abr. 2015.

ALMEIDA, A. T. Processo de decisão nas organizações: construindo modelos de decisão multicritério. São Paulo: Atlas, 2013.

ARAÚJO, A. G. de; ALMEIDA, A. T. de. Apoio à decisão na seleção de investimentos em petróleo e gás: uma aplicação utilizando o método PROMETHEE. Gestão \& Produção, v. 16, n. 4, p. 534-543, 2009.

BARBOSA, M. R. C. Microrregião de Sousa-PB: um estudo sobre as condições de geração de emprego e renda. 2017. Trabalho (Conclusão de Curso) - Universidade Federal da Paraíba, UFPB, 2017.

BEZERRA, V. V. N.; CARVALHO, J. R. M. Avaliação de desempenho por funções de governo através do método Promethee II. Contextus - Revista Contemporânea de Economia e Gestão, 16(3), p. 40-65, 2018.

BITTENCOURT, D. R. A guarda municipal e o direito fundamental à segurança. Jus Navigandi, Teresina, ano 18, n. 3.811, 7 dez. 2013. Disponível em: http://jus.com.br/artigos/26050. Acesso em: 28 dez. 2013.

BOGONI, N. M.; HEIN, N.; BEUREN, I. M. Análise da relação entre crescimento econômico e gastos públicos nas maiores cidades da região Sul do Brasil. Revista de Administração Pública, v. 45, n. 1, p. 159-179, jan./fev. 2011.

BORGES, F. Q. Administração pública do setor elétrico: indicadores de sustentabilidade no ambiente residencial do estado do Pará (2001-2010). Revista de Administração Pública, v. 46, n. 3, p. 737-751, maio/ jun. 2012.

BRAGA, B.; GOBETTI, L. Análise multiobjetivo. In: PORTO, Rubem La Laina (org.) et al. Técnicas quantitativas para o gerenciamento de recursos hídricos. 2. ed. Porto Alegre: Editora da UFRGS; Associação Brasileira de Recursos Hídricos, 2002. p. 361-418.

CARVALHO, J. R, M. de. Sistema de Indicadores para a Gestão de Recursos Hídricos em Municípios: uma abordagem através dos Métodos Multicritério e Multidecisor. Tese de Doutorado. Programa de Pós-Graduação em Recursos Naturais. Universidade Federal de Campina Grande, 2013, 255 f.

CARVALHO, J. R. M. de; CURI, W. F. Sistema de indicadores para a gestão de recursos hídricos em municípios: uma abordagem através dos métodos multicritério e multidecisor. In: SEMINÁRIOS EM ADMINISTRAÇÃO, 27., 2014, São Paulo. Anais [...]. São Paulo, SP: Universidade de São Paulo, 2014.

CARVALHO, J. R. M. de; CURI, W. F. Indicadores para a gestão dos recursos hídricos em municípios: uma proposta metodológica de construção e análise. E\&G Economia e Gestão, Belo Horizonte, v. 15, n. 38, p. 4-28, jan./mar. 2015.

CONTANDRIOPOULOS, A. P. et al. A avaliação na área da saúde: conceitos e métodos. In: HARTZ, Z. M. A. (org.). Avaliação em saúde: dos modelos conceituais à prática na análise da implantação de programas [on-line]. Rio de Janeiro: Editora Fiocruz, 1997. p. 29-47. Disponível em: http://books.scielo.org/id/3zcft/ pdf/hartz-9788575414033-04.pdf. Acesso em: 10 mar. 2020.

CRISPIM, G.; ATHERTON, L.; FERREIRA, C. D. Opportunity of robust research in Accounting: a literary analysis on performance indicators in the management of municipal governments. Contabilidad y Negocios, v. 14, n. 28, p. 126-142, 2019.

CURI, W. F.; CURI, R. C. Método AHP - Analytic Hierarchy Process. Material da disciplina de otimização em recursos naturais. 2010. Tese (Doutorado) - Universidade Federal de Campina Grande, Programa de Pós-Graduação em Recursos, Campina Grande, PB, ago./out. 2010.

DINIZ, J. A. D.; MACEDO, A. da S.; CORRAR, L. J. Mensuração da eficiência financeira municipal no Brasil e sua relação com os gastos nas funções de governo. Gestão \& Regionalidade, v. 28, n. 83, maio/ago. 2012. FARIA, C. A. P. de. A política da avaliação de políticas públicas. Revista Brasileira de Ciências Sociais, São Paulo, v. 20, n. 50, p. 97-169, out. 2005. 
FEITOSA, F. da F. População, ambiente e mudanças climáticas: reflexões sobre o desenvolvimento do Centro-Oeste brasileiro. Revista Brasileira de Estudos Populacionais, v. 29, n. 1, p. 209-211, 2012.

FERNANDES, M. A. da C. et al. Gasto social nas três esferas de governo - 1995. Brasília: Ipea, 1998.

GALERA, A. N.; RODRIGUEZ, D. O.; HERNANDEZ, A. M. L. Identifying barriers to the application of standardized performance indicators in local government. Public Management Review, v. 10, n. 2, 241-262, 2008.

GIL, A. C. Como elaborar projetos de pesquisa. 5. ed. São Paulo: Atlas, 2010.

GOMES, L. F. A. M.; GOMES, C. F. S.; ALMEIDA, A. T. de. Tomada de decisão gerencial: enfoque multicritério. 3 ed. rev. e ampl. São Paulo: Atlas, 2009. p. 324.

GONÇALVES, É.; BRAGA, F. M. S. A.; CAMPOS, E. S. A. Avaliação executiva de indicadores no governo do Estado de Minas Gerais: análise da implementação de uma ferramenta de monitoramento e avaliação. Revista de Administração Pública, v. 45, n. 6, p. 1.891-1.914, nov./dez. 2011.

JANNUZZI, P. de M. Indicadores para diagnóstico, monitoramento e avaliação de programas sociais no Brasil. Revista do Serviço Público Brasília, v. 56, n. 2, p. 137-160, abr./jun. 2005.

JOLLIVET, M.; PAVÉ, A. Meio ambiente: questões e perspectivas para a pesquisa. In: VIEIRA, P. F.; WEBER, J. Gestão de recursos naturais renováveis e desenvolvimento: novos desafios para a pesquisa ambiental. São Paulo: Cortez, 2002. p. 53-112.

KUHLMANN, S. Performance measurement in European local governments: A comparative analysis of reform experiences in great Britain, France, Sweden and Germany. International Review of Administrative Sciences, v. 76, n. 2, p. 331-345, 2010.

LIMA, M. S.; SANTOS, A. M. L. dos. Avaliação de desempenho da gestão pública baseada nos indicadores econômico-financeiros: um estudo de casos múltiplos em entidades federais indiretas do município de Manaus. Gestão \& Sociedade, v. 3, n. 5, jan./jun. 2009.

LUCENA, L. de F. L. A Análise multicriterial na avaliação de impactos ambientais. In: ENCONTRO DA SOCIEDADE BRASILEIRA DE ECONOMIA ECOLÓGICA, 3., 1999, Recife. Anais [...]. Recife, PE, 1999.

LYRA, R. L. W. C. de. Análise hierárquica dos indicadores contábeis sob a óptica do desempenho empresarial. 2008. Tese (Doutorado - Universidade de São Paulo, Departamento de Contabilidade e Atuária da Faculdade de Economia, Administração e Contabilidade, 2008.

MARCELLO, I. E. Análise dos indicadores sociais e econômicos nos municípios que possuem um câmpus da Universidade Federal da Fronteira Sul. Rev. Ciênc. Empres., Umuarama: Unipar, v. 15, n. 2, p. 203-214, jul./dez. 2014.

MARTINS, G. de A.; THEÓPHILO, C. R. Metodologia da investigação científica para ciências sociais e aplicadas. 2. ed. São Paulo: Atlas, 2009. p. 247.

MENDES, P. et al. Evaluating municipal solid waste management performance in regions with strong seasonal variability. Ecological Indicators, v. 30, p. 170-177. July 2013.

MOKATE, K. M. Convirtiendo el "monstruo" en aliado: la evaluación como herramienta de la gerencia social. Revista do Serviço Público, 8(1), p. 91-136, 2002.

MONTESINOS, V.; BRUSCA, I. Towards Performance, Quality and Environmental Management in Local Government: the Case of Spain. Local Government Studies, v. 35, n. 2, p. 197-212, 2009.

PARAÍBA. SIGAESA-WEB. Mapa da Microrregião de Sousa, PB. 2016. Disponível em: http://geo.aesa.pb. gov.br/download.phtml. Acesso em: 18 fev. 2016.

PARK, J. H. Does Citizen Participation Matter to Performance-Based Budgeting? Public Performance \& Management Review, v. 42(2), p. 280-304, 2019.

PEKKANEN, P.; NIEMI, P. Process performance improvement in justice organizations: Pitfalls of performance measurement. International Journal of Production Economics, v. 143, n. 2, p. 605-611, jun. 2013.

POMPERMAYER, R. de S. Aplicação da análise multicritério em gestão de recursos hídricos: simulação para as bacias dos Rios Piracicaba, Capivari e Jundiaí. 2003. Dissertação (Mestrado) - Universidade Estadual de Campinas, Faculdade de Engenharia Agrícola, Campinas, SP, 2003.

RAMOS, M. P.; SCHABBACH, L. M. O estado da arte da avaliação de políticas públicas: conceituação e exemplos de avaliação no Brasil. Revista de Administração Pública, v. 46, n. 5, p. 1.271-1.294, 2012.

RANGEL, L. A. D.; GOMES, L. F. A. M.; MOREIRA, R. A. Decision Theory With Multiple Criteria: An Application of Electre IV and Todim to SEBRAE/RJ. Revista Pesquisa Operacional, v. 29, n. 3, p. 577-590, set./dez. 2009.

RICHARDSON, R. J. et al. Pesquisa social métodos e técnicas. 3. ed. 7 reimp. São Paulo: Atlas, 2007.

ROGGE, N.; SELF, R. Measuring regional social inclusion performances in the EU: Looking for unity in diversity. Journal of European Social Policy, v. 29(3), p. 325-344, 2019. 
RUA, M. G. A avaliação de políticas, programas e projetos: notas introdutórias. 2010. Mimeo. Disponível em: https://www.trabalhosgratuitos.com/Sociais-Aplicadas/Pedagogia/RUA-G-M-Avalia\%C3\%A7\%C3\%A3o-de-Pol\%C3\%ADticas-Programas-e-1514774.html. Acesso em: 10 mar. 2020.

SILVA, J. T. M.; CABRERA, P. A. L.; TEIXEIRA, L. A. A. Aplicação do método de análise hierárquica no processo de tomada de decisão: um estudo com o empreendedor agrícola da Região de Divino/MG. Revista Gestão e Planejamento, Salvador, a. 7, n. 14, p. 19-30, 2006.

SILVA, C. R. M. da; CRISÓSTOMO, V. L. Gestão fiscal, eficiência da gestão pública e desenvolvimento socioeconômico dos municípios cearenses. Revista de Administração Pública, 53(4), p. 791-801, 2019.

SILVA, M. C.; SILVA, J. D. G. Ranking de desempenho da execução orçamentária por funções de governo dos 50 municípios mais populosos do Brasil em 2013 e determinação de suas funções significativas. InterScience Place - Revista Científica Internacional, n. 3, v. 10, artigo no 8, jul./set. 2015.

SOUZA, A. C. de; FIALHO, F. A. P.; OTANI, N. TCC - Métodos e Técnicas. Florianópolis: Visual Books, 2007. p. 160.

SPEKLÉ, R. F.; VERBEETEN, F. H. M. (2014). The use of performance measurement systems in the public sector: effects on performance. Management Accounting Research, v. 25, n. 2, p. 131-146, 2014.

STECCOLINI, I.; SALITERER, I.; GUTHRIE, J. The role(s) of accounting and performance measurement systems in contemporary public administration. Public Administration, v. 1, n. 1, p. 1-11, 2020.

WEBER, J. Gestão de Recursos renováveis: fundamentos teóricos de um programa de pesquisas. In: VIEIRA, P. F.; WEBER, J. (org.). Gestão de recursos naturais renováveis e desenvolvimento: novos desafios para a pesquisa ambiental. Tradução Anne Sophie de Pontbriand Vieira e Christilla de Lassus. 3. ed. São Paulo: Cortez, 2002. p. 115-146.

ZAMAN, K. et al. The relationship between financial indicators and human development in Pakistan. Economic Modelling, v. 29, n. 5, p. 1.515-1.523, Sept. 2012.

ZUCATTO, L. C. et al. Proposição de Indicadores de desempenho na gestão pública. ConTexto, Porto Alegre, v. 9, n. 16, 2o semestre 2009. 


\section{APÊNDICE - PARÂMETROS DE ESCOLHA DOS INDICADORES DO MO- DELO - SISTEMA DE INDICADORES PARA A GESTÃO PÚBLICA (SIGP)}

\begin{tabular}{|c|c|c|c|c|}
\hline \multicolumn{5}{|c|}{ SISTEMA DE INDICADORES DE GESTÃO PÚBLICA MUNICIPAL } \\
\hline Dimensão & Indicador & Fórmula & Objetivo & Relação \\
\hline \multirow[t]{4}{*}{ Financeira } & $\begin{array}{l}\text { Receita } \\
\text { Tributária } \\
\text { Arrecadada } \\
\text { per capita }\end{array}$ & $\begin{array}{l}\text { RTA per capita = } \\
\text { Receita Tributária } \\
\text { Arrecada/População } \\
\text { total estimada } 2014 .\end{array}$ & $\begin{array}{l}\text { Avaliar a capacidade do } \\
\text { gestor na arrecadação } \\
\text { de impostos. }\end{array}$ & $\begin{array}{l}\text { Positiva (Maximizar). Quanto } \\
\text { maior o indicador, melhor a } \\
\text { situação do município. } \\
\text { Fonte: Sagres on-line. } \\
\text { Disponível em: } \\
\text { http://sagres.tce.pb.gov.br/ }\end{array}$ \\
\hline & $\begin{array}{ll}\text { FPM } & \text { per } \\
\text { capita } & \end{array}$ & $\begin{array}{l}\text { FPM per capita = } \\
\text { FPM } \\
\text { arrecadado/Populaç } \\
\text { ão total estimada } \\
2014 .\end{array}$ & $\begin{array}{lr}\text { Avaliar a capacidade de } \\
\text { captação } & \text { de } \\
\text { transferências } & \\
\text { constitucionais } & \text { da } \\
\text { União. } & \end{array}$ & $\begin{array}{l}\text { Positiva (Maximizar). Quanto } \\
\text { maior o indicador, melhor a } \\
\text { situação do município. } \\
\text { Fonte: Sagres on-line. } \\
\text { Disponível em: } \\
\text { http://sagres.tce.pb.gov.br/ }\end{array}$ \\
\hline & $\begin{array}{ll}\text { ICMS } & \text { per } \\
\text { capita } & \end{array}$ & $\begin{array}{l}\text { ICMS per capita = } \\
\text { ICMS } \\
\text { arrecado/População } \\
\text { total estimada } 2014 .\end{array}$ & $\begin{array}{l}\text { Avaliar de captação de } \\
\text { transferências } \\
\text { constitucionais do } \\
\text { Estado. }\end{array}$ & $\begin{array}{l}\text { Positiva (Maximizar). Quanto } \\
\text { maior o indicador, melhor a } \\
\text { situação do município. } \\
\text { Fonte: Sagres on-line. } \\
\text { Disponível em: } \\
\text { http://sagres.tce.pb.gov.br/ }\end{array}$ \\
\hline & $\begin{array}{l}\text { Receita total } \\
\text { per capita }\end{array}$ & $\begin{array}{l}\text { Receita total per } \\
\text { capita }=\text { Receita total } \\
\text { arrecadada/Populaç } \\
\text { ão total estimada } \\
2014 .\end{array}$ & $\begin{array}{l}\text { Avaliar a capacidade de } \\
\text { arrecadação total da } \\
\text { administração pública. }\end{array}$ & $\begin{array}{l}\text { Positiva (Maximizar). Quanto } \\
\text { maior o indicador, melhor a } \\
\text { situação do município. } \\
\text { Fonte: Sagres on-line. } \\
\text { Disponível em: } \\
\text { http://sagres.tce.pb.gov.br/ }\end{array}$ \\
\hline \multirow[t]{3}{*}{ Social } & IDH-M & $\begin{array}{l}\text { O índice, } \\
\text { considerado aqui } \\
\text { como indicador, } \\
\text { varia de zero } \\
\text { (nenhum } \\
\text { desenvolvimento } \\
\text { humano) a } 1 \\
\text { (desenvolvimento } \\
\text { humano total). }\end{array}$ & $\begin{array}{l}\text { Esse indicador } \\
\text { apresenta sua } \\
\text { relevância, posto que } \\
\text { fornece um retrato do } \\
\text { nível de } \\
\text { desenvolvimento por } \\
\text { meio de aspectos de } \\
\text { educação, longevidade } \\
\text { e renda. }\end{array}$ & $\begin{array}{l}\text { Fonte: IBGE } \text { Banco de dados } \\
\text { @cidades, seleciona o } \\
\text { município. }\end{array}$ \\
\hline & $\begin{array}{ll}\text { Gastos } & \text { de } \\
\text { saúde } & \text { per } \\
\text { capita } & \end{array}$ & $\begin{array}{l}\text { Gastos de saúde per } \\
\text { capita = Gastos em } \\
\text { saúde/População } \\
\text { total estimada } 2014 .\end{array}$ & $\begin{array}{l}\text { Avaliar os gastos per } \\
\text { capita com saúde no } \\
\text { município. }\end{array}$ & $\begin{array}{l}\text { Positiva (Maximizar). Quanto } \\
\text { maior o indicador, melhor a } \\
\text { situação do município. } \\
\text { Fonte: Sagres on-line. } \\
\text { Disponível em: } \\
\text { http://sagres.tce.pb.gov.br/ }\end{array}$ \\
\hline & $\begin{array}{l}\text { Gastos em } \\
\text { educação } \\
\text { per capita }\end{array}$ & 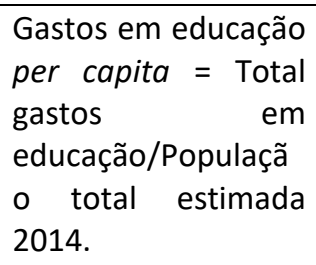 & $\begin{array}{l}\text { Avaliar os gastos per } \\
\text { capita com educação } \\
\text { no município. }\end{array}$ & $\begin{array}{l}\text { Positiva (Maximizar). Quanto } \\
\text { maior o indicador, melhor a } \\
\text { situação do município. } \\
\text { Fonte: Sagres on-line. } \\
\text { Disponível em: } \\
\text { http://sagres.tce.pb.gov.br/ }\end{array}$ \\
\hline
\end{tabular}




\begin{tabular}{|c|c|c|c|c|}
\hline & $\begin{array}{l}\text { Gastos em } \\
\text { transporte } \\
\text { per capita }\end{array}$ & $\begin{array}{l}\text { Gastos em } \\
\text { transporte per } \\
\text { capita = Total gasto } \\
\text { em } \\
\text { transporte/Populaçã } \\
\text { o total estimada } \\
2014 .\end{array}$ & $\begin{array}{l}\text { Avaliar os gastos per } \\
\text { capita com transporte } \\
\text { no município. }\end{array}$ & $\begin{array}{l}\text { Positiva (Maximizar). Quanto } \\
\text { maior o indicador, melhor a } \\
\text { situação do município. } \\
\text { Fonte: Sagres on-line. } \\
\text { Disponível em: } \\
\text { http://sagres.tce.pb.gov.br/ }\end{array}$ \\
\hline & $\begin{array}{l}\text { Gastos em } \\
\text { segurança } \\
\text { per capita }\end{array}$ & $\begin{array}{l}\text { Gastos em } \\
\text { segurança per capita } \\
=\text { Total gasto em } \\
\text { segurança/Populaçã } \\
\text { o total. }\end{array}$ & $\begin{array}{l}\text { Avaliar os gastos per } \\
\text { capita com segurança } \\
\text { no município. }\end{array}$ & $\begin{array}{l}\text { Positiva (Maximizar). Quanto } \\
\text { maior o indicador, melhor a } \\
\text { situação do município. } \\
\text { Fonte: Sagres on-line. } \\
\text { Disponível em: } \\
\text { http://sagres.tce.pb.gov.br/ }\end{array}$ \\
\hline & $\begin{array}{l}\text { Gastos em } \\
\text { urbanismo } \\
\text { per capita }\end{array}$ & 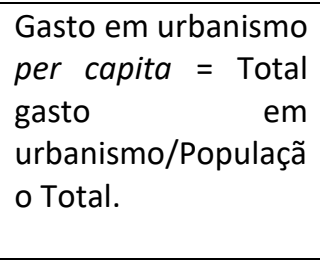 & $\begin{array}{l}\text { Avaliar os gastos per } \\
\text { capita com urbanismo } \\
\text { no município. }\end{array}$ & $\begin{array}{l}\text { Positiva (Maximizar). Quanto } \\
\text { maior o indicador, melhor a } \\
\text { situação do município. } \\
\text { Fonte: Sagres on-line. } \\
\text { Disponível em: } \\
\text { http://sagres.tce.pb.gov.br/ }\end{array}$ \\
\hline & $\begin{array}{l}\text { Gastos em } \\
\text { assistência } \\
\text { social per } \\
\text { capita }\end{array}$ & $\begin{array}{l}\text { Gasto em assistência } \\
\text { social per capita = } \\
\text { Total gasto em } \\
\text { assistência } \\
\text { social/População } \\
\text { Total. }\end{array}$ & $\begin{array}{l}\text { Avaliar os gastos per } \\
\text { capita com assistência } \\
\text { social no município. }\end{array}$ & $\begin{array}{l}\text { Positiva (Maximizar). Quanto } \\
\text { maior o indicador, melhor a } \\
\text { situação do município. } \\
\text { Fonte: Sagres on-line. } \\
\text { Disponível em: } \\
\text { http://sagres.tce.pb.gov.br/ }\end{array}$ \\
\hline & $\begin{array}{l}\text { Gastos em } \\
\text { habitação } \\
\text { per capita }\end{array}$ & $\begin{array}{l}\text { Gasto em habitação } \\
\text { per capita = Total } \\
\text { gasto em } \\
\text { habitação/Populaçã } \\
\text { o Total. }\end{array}$ & $\begin{array}{l}\text { Avaliar os gastos per } \\
\text { capita com habitação } \\
\text { no município. }\end{array}$ & $\begin{array}{l}\text { Positiva (Maximizar). Quanto } \\
\text { maior o indicador, melhor a } \\
\text { situação do município. } \\
\text { Fonte: Sagres on-line. } \\
\text { Disponível em: } \\
\text { http://sagres.tce.pb.gov.br/ }\end{array}$ \\
\hline & $\begin{array}{ll}\text { Gastos } & \text { em } \\
\text { cultura } & \text { per } \\
\text { capita } & \end{array}$ & $\begin{array}{l}\text { Gasto em cultura per } \\
\text { capita = Total gasto } \\
\text { em } \\
\text { cultura/População } \\
\text { Total. }\end{array}$ & $\begin{array}{l}\text { Avaliar os gastos per } \\
\text { capita com cultura no } \\
\text { município. }\end{array}$ & $\begin{array}{l}\text { Positiva (Maximizar). Quanto } \\
\text { maior o indicador, melhor a } \\
\text { situação do município. } \\
\text { Fonte: Sagres on-line. } \\
\text { Disponível em: } \\
\text { http://sagres.tce.pb.gov.br/ }\end{array}$ \\
\hline Ambiental & $\begin{array}{l}\text { Gastos em } \\
\text { saneamento } \\
\text { per capita }\end{array}$ & $\begin{array}{l}\text { Gasto em } \\
\text { saneamento per } \\
\text { capita = Total gasto } \\
\text { em } \\
\text { cultura/População } \\
\text { Total. }\end{array}$ & $\begin{array}{lr}\text { Avaliar os gastos per } \\
\text { capita } & \text { com } \\
\text { saneamento } & \text { no } \\
\text { município. } & \end{array}$ & $\begin{array}{l}\text { Positiva (Maximizar). Quanto } \\
\text { maior o indicador, melhor a } \\
\text { situação do município. } \\
\text { Fonte: Sagres on-line. } \\
\text { Disponível em: } \\
\text { http://sagres.tce.pb.gov.br/ }\end{array}$ \\
\hline & $\begin{array}{l}\text { Gastos em } \\
\text { gestão } \\
\text { ambiental } \\
\text { per capita }\end{array}$ & $\begin{array}{l}\text { Gasto em cultura = } \\
\text { Total gasto em } \\
\text { gestão } \\
\text { ambiental/Populaçã } \\
\text { o Total. }\end{array}$ & $\begin{array}{lr}\text { Avaliar os gastos per } \\
\text { capita com gestão } \\
\text { ambiental } \\
\text { município. }\end{array}$ & $\begin{array}{l}\text { Positiva (Maximizar). Quanto } \\
\text { maior o indicador, melhor a } \\
\text { situação do município. } \\
\text { Fonte: Sagres on-line. } \\
\text { Disponível em: } \\
\text { http://sagres.tce.pb.gov.br/ }\end{array}$ \\
\hline
\end{tabular}




\begin{tabular}{|c|c|c|c|}
\hline $\begin{array}{l}\text { Existência de } \\
\text { aterro } \\
\text { sanitário no } \\
\text { município ou } \\
\text { se no } \\
\text { município } \\
\text { existe } \\
\text { projeto de } \\
\text { construção. }\end{array}$ & $\begin{array}{l}\text { (0) Não tem aterro } \\
\text { sanitário } \\
(0,5) \text { Em fase de } \\
\text { discussão ou } \\
\text { estabelecimento } \\
\text { (1) Existe aterro } \\
\text { sanitário. }\end{array}$ & $\begin{array}{l}\text { A existência de aterro } \\
\text { sanitário é } \\
\text { fundamental das } \\
\text { avaliação } \\
\text { condições de saúde da } \\
\text { população. O uso desse } \\
\text { indicador justifica-se } \\
\text { pelo fato de o aterro } \\
\text { sanitário ser o local } \\
\text { adequado lixo } \\
\text { armazenar o lara } \\
\text { coletado, capaz de } \\
\text { inibir a proliferação de } \\
\text { problemas ocasionados } \\
\text { pela má gestão do lixo, } \\
\text { o que supostamente } \\
\text { pode afetara qualidade } \\
\text { da água, caso não haja } \\
\text { um manejo adequado } \\
\text { dos resíduos. }\end{array}$ & $\begin{array}{l}\text { Relação: Positiva (Maximizar). } \\
\text { Fonte: Informação } \\
\text { disponibilizada pelo órgão } \\
\text { responsável no município ou } \\
\text { Atlas de saneamento. } \\
\text { Origem dos dados: Primários. }\end{array}$ \\
\hline $\begin{array}{l}\text { Domicílios } \\
\text { particulares } \\
\text { permanente } \\
\text { s - tipo de } \\
\text { saneamento } \\
\text { - totais - } \\
\text { adequados }\end{array}$ & $\begin{array}{l}\text { Percentual de } \\
\text { domicílios } \\
\text { particulares } \\
\text { permanentes - tipo } \\
\text { de saneamento. }\end{array}$ & $\begin{array}{l}\text { Seu uso justifica-se, } \\
\text { uma vez que revela } \\
\text { fragilidades que podem } \\
\text { ser discutidas e } \\
\text { melhoradas quando se } \\
\text { apresenta baixos níveis } \\
\text { desse percentual, } \\
\text { denotando a } \\
\text { necessidade de definir } \\
\text { políticas públicas mais } \\
\text { alinhadas à gestão de } \\
\text { resíduos sólidos do } \\
\text { município. }\end{array}$ & $\begin{array}{l}\text { Relação: Positiva (Maximizar). } \\
\text { Fonte: IBGE, Censo } \\
\text { Demográfico/Indicadores } \\
\text { Sociais Municipais, 2010. } \\
\text { Origem dos dados: } \\
\text { Secundários. }\end{array}$ \\
\hline $\begin{array}{l}\text { Índice de } \\
\text { Atendiment } \\
\text { o Total de } \\
\text { Água }\end{array}$ & 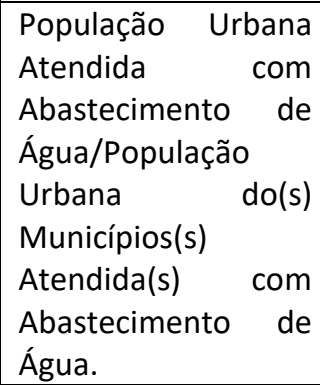 & $\begin{array}{l}\text { Identifica o percentual } \\
\text { da população total do } \\
\text { município abastecida. }\end{array}$ & $\begin{array}{l}\text { Relação: Positiva (Maximizar) } \\
\text { Fonte: SNIS, 2013. Disponível } \\
\text { em: } \\
\text { http://www.snis.gov.br/Pagin } \\
\text { aCarrega.php?EWRErterterTE } \\
\text { RTer=105 }\end{array}$ \\
\hline
\end{tabular}

